Article

\title{
Characterization and Beneficiation Options for Tungsten Recovery from Yxsjöberg Historical Ore Tailings
}

\author{
Jane Mulenshi ${ }^{1, * \mathbb{D}}$, Pourya Khavari, Saeed Chehreh Chelgani and Jan Rosenkranz \\ Division of Minerals and Metallurgical Engineering, Luleå University of Technology, Luleå SE-971 87, Sweden; \\ pouryakhavari@gmail.com (P.K.); saeed.chelgani@ltu.se (S.C.C.); jan.rosenkranz@ltu.se (J.R.) \\ * Correspondence: jane.mulenshi@ltu.se; Tel.: +46-920-493673
}

Received: 31 October 2019; Accepted: 23 November 2019; Published: 2 December 2019

check for updates

\begin{abstract}
Repositories of historical tungsten mining tailings pose environmental risks, but are also potential resources for valuable metals. They still contain large tonnages of useful minerals and metals, reflecting the inefficient extraction methods and/or low metal prices at the time they were mined. The focus of this study is to evaluate the technical viability of reprocessing the tailings to recover some of the contained valuable minerals and metals, as well as reducing the negative environmental impact associated with the tailings. Geometallurgical studies were conducted on drill core samples taken from the Smaltjärnen tailings repository of the closed Yxsjöberg tungsten mine, Sweden. The collected samples were characterized physically, chemically, and mineralogically. Knelson concentrator dry low- and high-intensity magnetic separation methods were tested as potential beneficiation methods. The tailings are dominated by the -600 to $+149 \mu \mathrm{m}$ particles. The highest concentration of tungsten (W) was $0.22 \% \mathrm{WO}_{3}$. Using a Knelson concentrator, scheelite (main W mineral) recovery was enhanced, with $75 \mathrm{wt}$ \% $\%$ tungsten recovered in the $34 \mathrm{wt}$ \% heavy concentrate. Only $1.0 \mathrm{wt} . \%$ sulphur (S) reported to the non-magnetic fraction. Based on the findings, a methodology and a preliminary process flowsheet for reprocessing the tailings is proposed.
\end{abstract}

Keywords: historical tailings; Tungsten; Scheelite; geometallurgical approach; characterization; beneficiation; reprocessing

\section{Introduction}

Tungsten $(\mathrm{W})$ is among the critical raw materials with significant economic importance and high supply risk for the European Union [1]. According to the 2015 risk list of the British Geological Survey, tungsten has a relative supply risk index of 8.1 on a scale of 1 to 10 , which ranks sixth behind rare earth elements that have the highest risk [2]. Primarily, tungsten is produced from scheelite and wolframite ores with $0.08-1.5 \%$ tungsten trioxide $\left(\mathrm{WO}_{3}\right)$ [3]. These tungsten minerals are friable in nature compared to the associated gangue minerals; hence, fine tungsten particles are excessively generated during the necessary comminution processes. The fine tungsten particles are lost to tailings due to the failure of commonly used separation methods to recover fine tungsten minerals particles [3,4]. Thus, for critical raw materials with a high supply risk such as tungsten, old tailings storage facilities (TSF) are potential sources for additional production. Globally, historical tailings (HT) recycling is being considered as a supply risk-reducing measure [1]. Apart from being potential resources, HT repositories also pose environmental risks [5-7]. Hence, there is need for a holistic reprocessing approach in which not only the valuable minerals will be recovered, but also the environmental risk will be reduced, leaving an inert and environmentally safe residue [7]. 
HT repositories can be considered as geometallurgical units based on the definition of being "an ore type or group of ore types that possess a unique set of textural and compositional properties from which it can be predicted that they will have similar metallurgical performance" [8]. Accordingly, various geometallurgical and/or process mineralogical approaches have been used to investigate process tailings or processed ores $[6,9-13]$. TSF may have several geometallurgical units depending on what type of primary ore and which process streams the tailings were generated from, how the deposition was done (randomly or systematically), and the weathering that could have occurred over time. Concerning weathering, sulphide minerals are prone to oxidation, especially near the tailings surface, resulting in a series of reactions that produce acidic pore water and ferric-bearing secondary precipitates that may contain high concentrations of metals, either co-precipitated with or adsorbed onto ferric (oxy) hydroxides $[14,15]$. For tungsten tailings, low $\mathrm{pH}$ due to acid pore water in the tailings increases $\mathrm{W}$ affinity for hydrous ferric oxides (HFOs), and when it forms polyoxyanion species, its mobility in the aquatic environment is enhanced [16]. Therefore, for HT with a long storage period, these geochemical changes may alter the chemical composition of tailings compared to the primary ore from which they were produced [17]. This may lead to the reprocessing flowsheets and metallurgical performances of tailings being different from those of primary ores from which they were initially produced. Moreover, the amount of valuable minerals in HT depends largely on the initially employed beneficiation methods and their efficiencies. For instance, for high density ores such as scheelite ores, gravity separation and flotation methods are conventionally used, and depending on the associated minerals, magnetic separation may also be used [18]. Because of the excessive generation of fine scheelite particles which are partly lost to the tailings during comminution, advanced multi-stage gravity separation techniques, good for processing fine particles, should be considered in order to efficiently recover heavy fines during reprocessing of the tailings [19].

In this study, historical tailings from the Smaltjärnen TSF at the closed Yxsjöberg tungsten mine in Middle Sweden were analyzed and tested in a case study that investigated the feasibility of reprocessing the tailings not only as a supply risk-reducing measure, but also as a possible remediation method. In addition to tungsten, other elements of economic importance and with elevated concentrations in the tailings under study include copper $(\mathrm{Cu})$, fluorspar $\left(\mathrm{CaF}_{2}\right)$, sulphur $(\mathrm{S})$, tin $(\mathrm{Sn})$, zinc $(\mathrm{Zn})$, beryllium $(\mathrm{Be})$, and bismuth (Bi) [20]. Eventual extraction of these elements and safe disposal of the remaining residue require a detailed understanding of the mineralogical, geochemical, and bulk physical properties of the tailings [7,21]. Preliminary mineralogical and geochemical studies of the tailings revealed that $\mathrm{W}, \mathrm{Cu}$, F, S, Sn, Zn, Be, and Bi are hosted mainly in scheelite, chalcopyrite, fluorspar, pyrrhotite, cassiterite, danalite (both $\mathrm{Zn}$ and Be), and bismuthinite, respectively [20]. The analyses also showed that pyrrhotite was the main $\mathrm{Fe}$-sulphide mineral responsible for acid mine drainage (AMD) and need to be sequestered from the bulk tailings as a remediation measure.

The objectives of the current study are (1) to propose a methodology to understand further the properties (physical, chemical, and mineralogical) of the Yxsjöberg HT and how these are spatially distributed in the TSF, and (2) to determine the processing options for the tailings. These objectives will be achieved through (1) TSF characterization (sequential characterization of tailings), (2) metallurgical test work (selection of feasible reprocessing methods, e.g., physical separation), and (3) process design and analysis (flowsheet design). The results of this initial study will be decisive for the development of methods for separating valuable and environmentally deleterious minerals from HT, leaving a stable environmentally safe residue.

\section{Materials and Methods}

\subsection{The Yxsjöberg Mine}

One of the most important mining areas in northern Europe with regard to tungsten ores has been the Bergslagen district in Middle Sweden, where the Yxsjöberg historical tungsten ore tailings repository is located. The tailings in this study were produced from the ore that was mined at the Yxsjöberg 
mine from 1935 to 1963 , with average ore grades of $0.3-0.4 \mathrm{wt} . \% \mathrm{WO}_{3}, 0.2 \mathrm{wt} . \% \mathrm{Cu}$, and $5-6 \mathrm{wt} . \%$ fluorspar [22,23]. The exploited minerals were scheelite for $\mathrm{W}$, chalcopyrite for $\mathrm{Cu}$ and fluorspar. This repository is estimated to have about 2.2 million tons of tailings and covers an area of 26 hectares, with elemental concentrations of $1-2$ wt. $\%$ S, $0.02-0.2$ wt. $\%$ Cu, $0.02-0.3$ wt. $\% \mathrm{~W}, 0.02-0.04$ wt. $\%$ Sn, and $0.02-0.03 \mathrm{wt} . \%$ Be. The scheelite grain size in the ore was $0.2-4.0 \mathrm{~mm}$ and $90 \mathrm{wt} . \%$ of the ore was liberated at $0.4 \mathrm{~mm}$ particle size. The concentrate recoveries at that time were $50-70 \mathrm{wt} . \%$ for scheelite, $50 \mathrm{wt} . \%$ for fluorspar, and $25 \mathrm{wt} . \%$ for chalcopyrite, and a considerable amount of valuable minerals ended up in the tailings [23]. The Yxsjöberg processing plant had three main sections, namely gravity separation, magnetic separation, and flotation, from which tailings were generated and discharged onto the Smaltjärnen tailings repository (see Figure 1). Tailings deposition was done through several pipes, thus producing homogenous layers of tailings equally distributed over the width of the repository surface. No data were available that could be used to link these layers to the former production schedule.

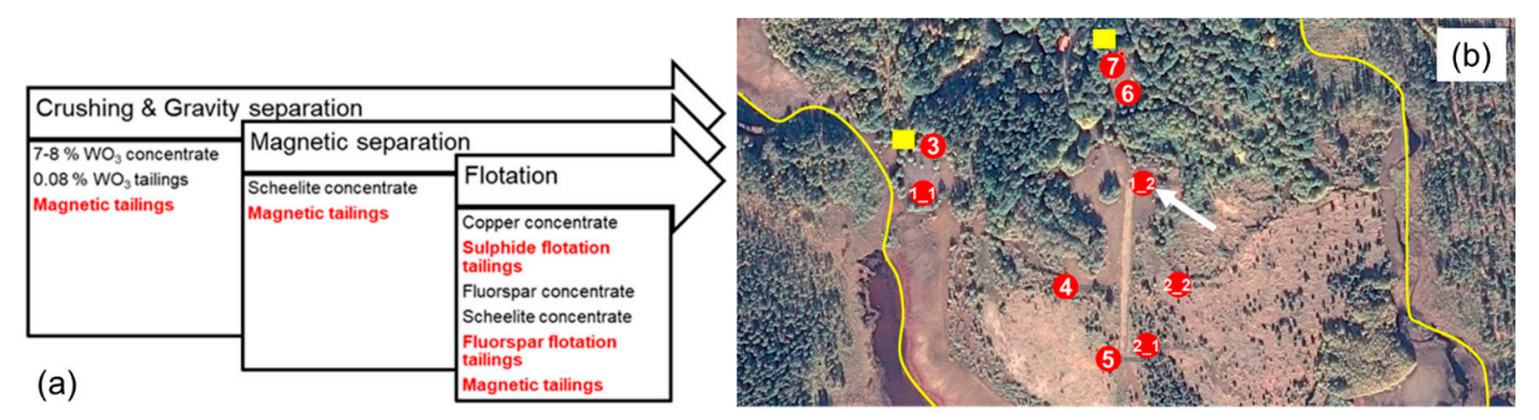

Figure 1. (a) Processes from which the Yxsjöberg historical tailings were generated. (b) Drill core sampling locations on the Smaltjärnen tailings storage facilities (TSF) represented by red dots; the yellow squares show two discharge points, the yellow lines show the repository boundary, and the white arrow shows the focus area for this study.

\subsection{Sampling and Sample Preparation}

Drill core samples were taken from nine different locations, shown in Figure 1b. Samples were collected mainly along the main discharge flow directions. The red dots represent the individual drill core sampling locations and the numbering of the sampling locations was based on the sequence of sampling in each sampling campaign. The first four locations were distinguished by _1 and _2, meaning $1 \_1$ was in the first campaign while $1 \_2$ was in the second campaign. For locations $1 \_2$ to 7, a percussion drill rig from Envix Nord $A B$ was used with plexiglass tubes $(40 \mathrm{~mm}$ diameter and $1.2 \mathrm{~m}$ length each tube) to hold the sample. The sampled locations were selected based on the visual variations of the tailings in terms of color and granulometry, and the proximity to former discharge points (Figure 1). It should be noted that the drill core from sampling location $1 \_2$ shown by the white arrow in Figure $1 \mathrm{~b}$ is the focus of this study. This location is very close to the P4 sampling location referred to in the geochemical characterization of these historical tailings [20].

The actual sampling points in the selected locations were randomly picked, and a summary of the information about one sampling point used in this paper is given in Table 1. Screening of the drill core was done based on the differences in color and granulometry in the core, and the drill core was divided into sub-samples representing tailing layers in this particular location of the repository. The thickness of each observed compacted layer was noted to have its approximate thickness in the tailing repository. The vertical profile showing the different layers in the tailings in the selected location of the repository is shown in Figure 2. Each color represents a separate layer of the of the tailings and its compacted thickness. Eleven layers were observed at sampling point 1_2, where the total compacted tailing thickness in the $600 \mathrm{~cm}$ drill hole was approximately $500 \mathrm{~cm}$. Since each plexiglass tube was only $1.2 \mathrm{~m}$ long, five pieces of drill cores were recovered from the drill hole. 
Table 1. Information of sampling point 1_2.

\begin{tabular}{cccccc}
\hline $\begin{array}{c}\text { Sampling } \\
\text { Point }\end{array}$ & Sampling Points GPS Coordinates & $\begin{array}{c}\text { Altitude } \\
(\mathbf{m})\end{array}$ & $\begin{array}{c}\text { Number of } \\
\text { Drill Holes }\end{array}$ & $\begin{array}{c}\text { Drill Hole } \\
\text { Depth (m) }\end{array}$ & $\begin{array}{c}\text { Number of } \\
\text { Drill Cores }\end{array}$ \\
\cline { 2 - 3 } DD (Decimal Degrees) & 306 & 1 & 6.0 & 5 \\
\hline
\end{tabular}

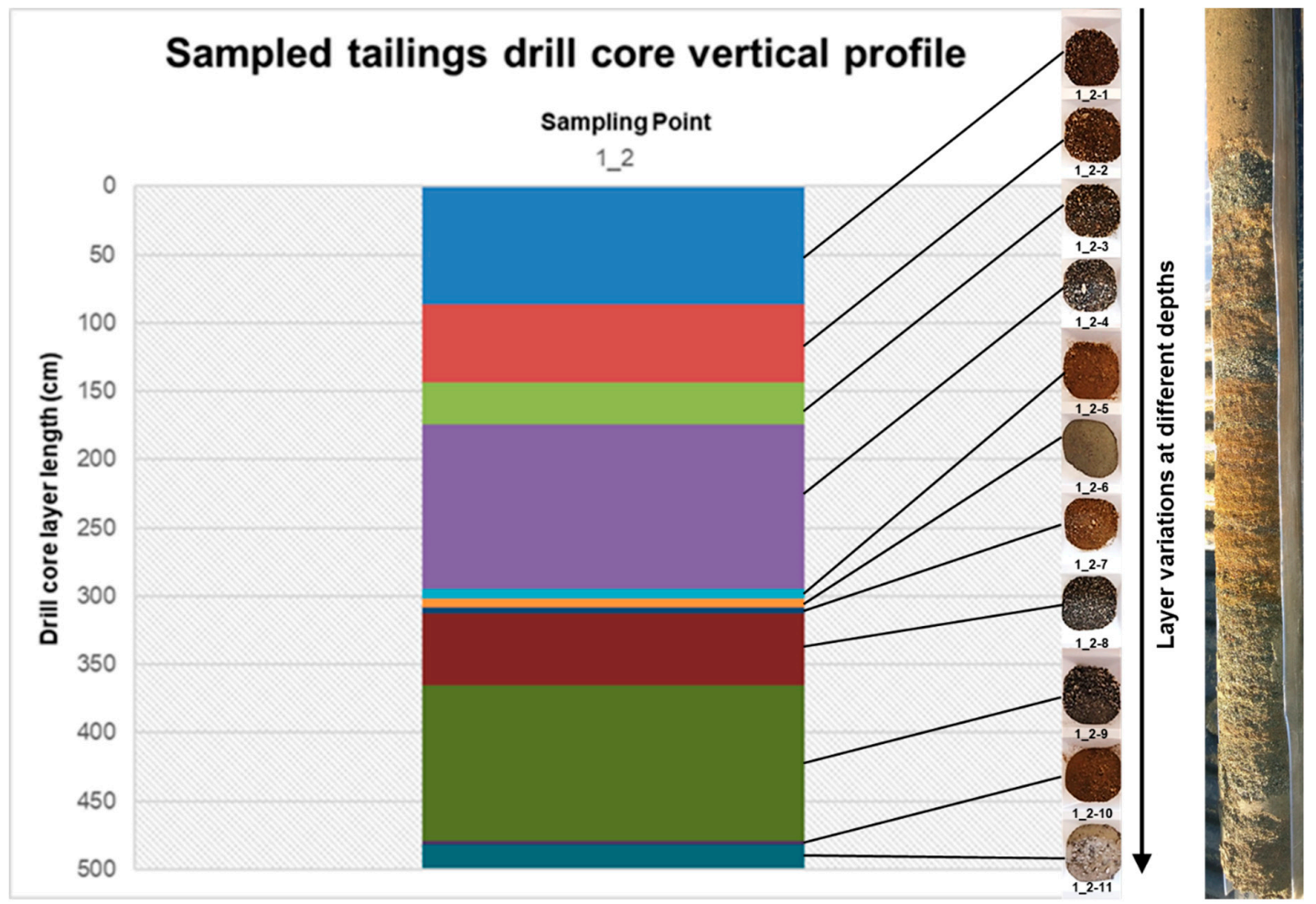

Figure 2. Vertical profile at sampling point 1_2. On the far right is a photo of one of the five drill core pieces in the cut plexiglass tube and before dividing the core into subsamples.

Prior to the physical and chemical analyses, the samples were dried at $105^{\circ} \mathrm{C}$ for $48 \mathrm{~h}$ to ensure complete drying, as there was a large volume of sample in each drying pan. The dried samples were then split into subsamples using a riffle splitter. Figure 2 also shows respective pictures of the dried samples from sampling point 1_2. In order to account for the different layers, in addition to the numbering of the sampling location, a number was added to denote the layers from top to bottom of a drill core (i.e., 1_2-1 means the first (top) layer in drill core 1 of the second campaign).

One hundred and fifty grams split of dried samples were collected from each layer and analyzed using a RO-TAP ${ }^{\circledR}$ Sieve Shaker model RX-29 with five sieves to obtain six size fractions. The total amount of available samples from layers 1_2-5, 1_2-6, 1_2-7, and 1_2-10 was less than $150 \mathrm{~g}$; hence, the samples were sieved without replication, which was done with the bigger samples to check that the split samples were representative of the whole layer sample.

\subsection{Characterization of Drill Core Samples}

The six size fractions obtained from the dry sieving were $>1190 \mu \mathrm{m},-1190$ to $+600 \mu \mathrm{m},-600$ to $+297 \mu \mathrm{m},-297$ to $+149 \mu \mathrm{m},-149$ to $+75 \mu \mathrm{m}$, and $<75 \mu \mathrm{m}$. Particle size distribution curves for each drill core layer and, subsequently, the entire drill core were determined. Using the Rosin-RammlerSperling-Bennett (RRSB) distribution function, the $\mathrm{D}_{80}$ of particle size was determined for each drill core layer, which gives more precise values than interpolating from the particle size distribution (PSD) curves. Small samples of approximately $15 \mathrm{~g}$ were split from each particle size fraction and bulk samples (1_2-5, 1_2-6, 1_2-7, and 1_2-10 layers that were less than $150 \mathrm{~g}$ ) of each drill core layer were 
chemically analyzed using the inductively coupled plasma-sector field mass spectrometry (ICP-SFMS) method. The "MG-2 + Bi Metals in waste" package analysis protocol, which included 10 oxides and 22 elements (namely $\mathrm{SiO}_{2}, \mathrm{Al}_{2} \mathrm{O}_{3}, \mathrm{CaO}, \mathrm{Fe}_{2} \mathrm{O}_{3}, \mathrm{~K} 2 \mathrm{O}, \mathrm{MgO}, \mathrm{MnO}, \mathrm{Na}_{2} \mathrm{O}, \mathrm{P}_{2} \mathrm{O}_{5}, \mathrm{TiO}_{2}, \mathrm{As}, \mathrm{Ba}, \mathrm{Be}, \mathrm{Bi}, \mathrm{Cd}$, $\mathrm{Co}, \mathrm{Cr}, \mathrm{Cu}, \mathrm{Hg}$, Mo, Nb, Ni, Pb, S, Sc, Sn, Sr, V, W, Y, Zn, and $\mathrm{Zr}$ ) was used.

The mineralogical composition was characterized by X-ray Diffraction (XRD) using a PANalytical Empyrean X-ray diffractometer (PANalytical B.V., Almelo, The Netherlands). Drill core layers 1_2-1, $1 \_2-4,1 \_2-8$, and 1_2-9 were selected for this analysis as they had the highest mass distributions in this drill core, as shown in Figure 3. Small samples (i.e., less than $50 \mathrm{~g}$ ) of these selected layers were pulverized in a ring mill to obtain the powder samples required for XRD analysis. The raw data obtained from the diffractometer were evaluated using the PANalytical X'Pert HighScore Plus v3.0 software (3.0d (3.0.4), PANalytical B.V., Almelo, The Netherlands, 2011).

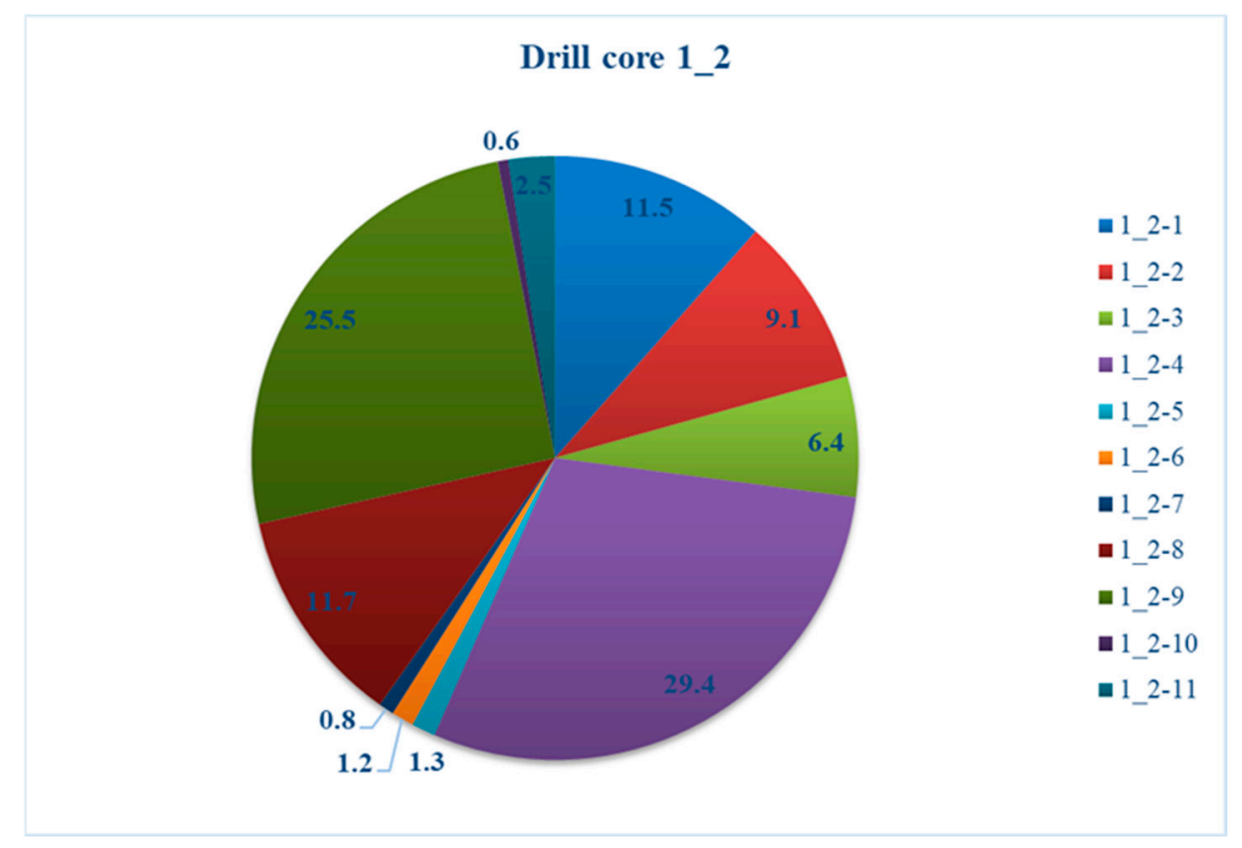

Figure 3. Mass distribution (\%) of tailings layers in drill core 1_2.

A ZEISS Axiophot Fluorescent Microscope (ZEISS, Oberkochen, Germany) mounted with an Infinity HD Camera was used for optical microscopy to study the scheelite (as the main mineral of interest) particles in the tailings with regard to occurrence, texture, and liberation. The fluorescence property of scheelite mineral was used to identify the scheelite particles and the blue filter was found to be effective in distinguishing scheelite particles from other minerals of similar luminance and brightness, such as bismuthinite. For this study, a grain mount polished section was prepared from a composite sample comprising $-3 \mathrm{~g}$ from each layer. The ZEISS MERLIN ${ }^{\mathrm{TM}}$ FE-SEM (Field Emission-Scanning Electron Microscope: ZEISS, Oberkochen, Germany) equipped with Energy-Dispersive X-ray Spectroscopy (EDS) and Back Scattered Electron (BSE) imaging was used to study the minerals in the drill core layers 1_2-4 and 1_2-9, which were the two layers with enough sample material. BSE images were captured and analyzed using the INCA-Oxford Instruments software (5.05, Oxford Instruments, High Wycombe, England, 2014). The distinction between scheelite and bismuthinite particles was confirmed using SEM-EDS chemical composition.

The above characterization methods for the drill core samples are summarized in Figure 4. 


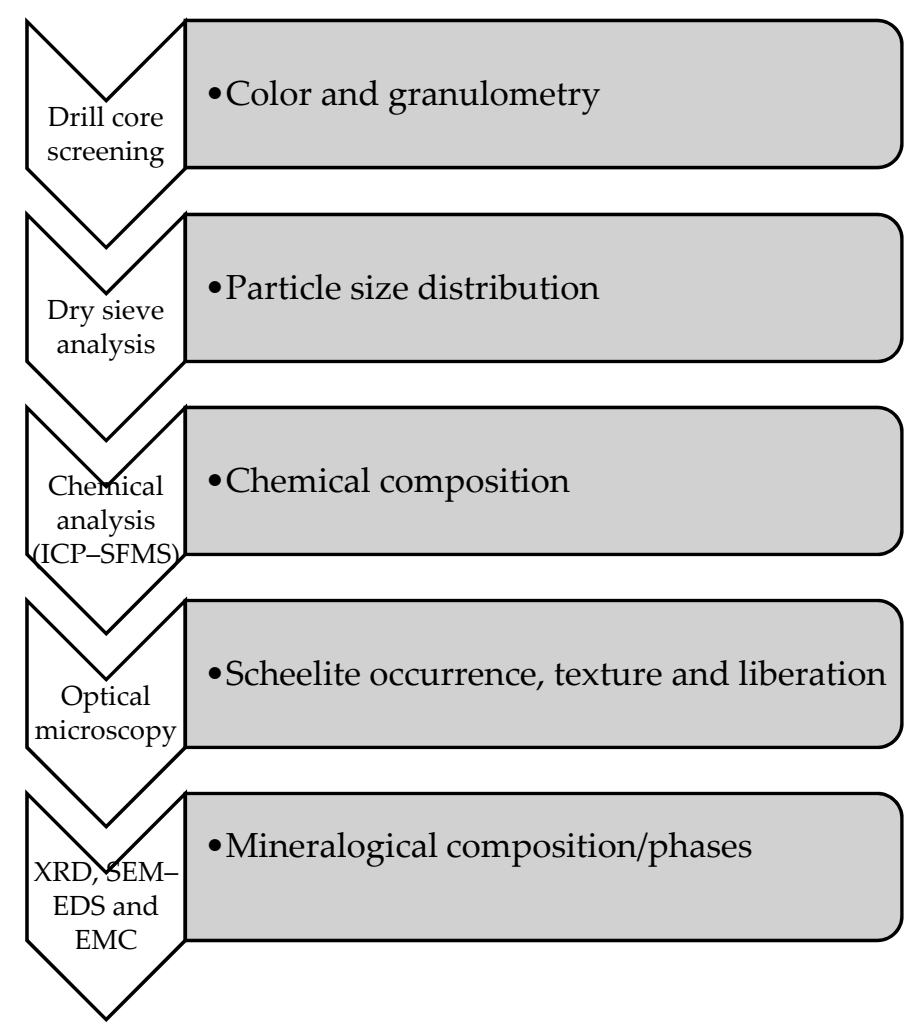

Figure 4. Summary of the characterization sequence of drill core samples.

\subsection{Physical Separation Test Work}

Magnetic and gravity separation were pre-selected as feasible physical separation methods based on literature, tailings characteristics, and assessment of processes from which the Yxsjöberg HT were produced.

\subsubsection{Magnetic Separation}

Magnetic separation test was conducted on two samples from layers 1_2-4 and 1_2-8. The test was conducted on the $+75 \mu \mathrm{m}$ and required at least $150 \mathrm{~g}$ of material. The samples were tested using both dry low-intensity magnetic separation (LIMS) and high-intensity magnetic separation (HIMS). During the LIMS, the drum speed and feed rate were varied, and during the HIMS, it was the splitter position that was varied. The process was assessed by observing the uniformity in the color of the products. Table 2 summarizes the operating parameters of both methods. The flowsheet in Figure 5 shows the magnetic separation test.

Table 2. Magnetic separation operating parameters [24].

\begin{tabular}{ccccc}
\hline \multirow{2}{*}{ Methods } & \multicolumn{4}{c}{ Variables } \\
\cline { 2 - 5 } & Motor (0-100) & Vibrator (0-100) & Plane 1 (-5, +5) & Plane 2 (-5, +5) \\
\hline LIMS & 100 & 70 & Fixed & N.A. (Not Applicable) \\
HIMS & Fixed & Fixed & 3 & -1 \\
\hline
\end{tabular}




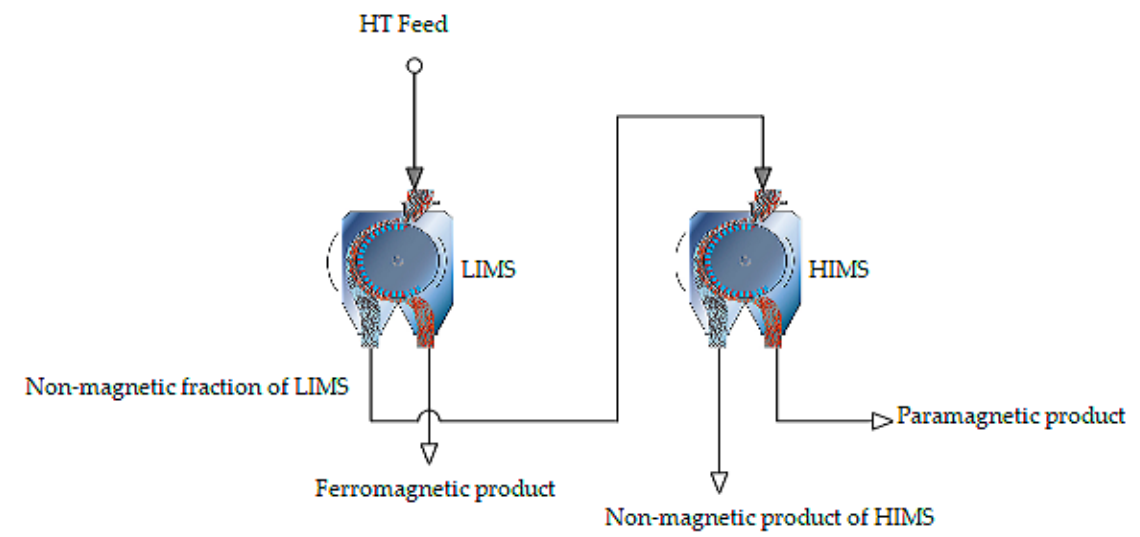

Figure 5. The simplified flowsheet of magnetic separation process: dry low-intensity magnetic separation (LIMS) and high-intensity magnetic separation (HIMS).

\subsubsection{Gravity Separation}

Samples 1_2-1 and 1_2-8 were tested separately for their susceptibility to gravity separation. The tests required less than $2 \mathrm{~kg}$ of the -600 to $+38 \mu \mathrm{m}$ fraction. A $58 \mathrm{~mL}$ laboratory scale Knelson concentrator at the Boliden $\mathrm{AB}$ laboratory was used, with operating parameters set as shown in Table 3.

Table 3. Knelson concentrator operating parameters [24].

\begin{tabular}{cccc}
\hline $\begin{array}{c}\text { Drum Speed } \\
(\mathbf{r p m})\end{array}$ & $\begin{array}{c}\text { Centrifugal Force } \\
(\mathbf{G})\end{array}$ & $\begin{array}{c}\text { Fluidization Water Flow Rate } \\
(\mathbf{L} / \mathbf{m i n})\end{array}$ & $\begin{array}{c}\text { Fluidization Water Pressure } \\
(\mathbf{k P a})\end{array}$ \\
\hline 1500 & 60 & 3.5 & 2 \\
\hline
\end{tabular}

The separation products were analyzed for their chemical composition at ALS Scandinavia AB in Luleå, Sweden using the ICP-SFMS method. Element-to-mineral conversion (EMC) algorithms of the HSC chemistry software (9.5.1, Outotec, Pori, Finland, 2018) were used to determine the minerals in the magnetic separation products based on their chemical composition.

\section{Results and Discussion}

\subsection{Characterization of Drill Core Samples}

The physical and chemical characterization of the HT showed variations occurring in the different layers of the drill cores, which revealed the variability at different depths of this repository location. In terms of moisture content, some of the upper tailing layers had higher moisture content than lower layers (Figure 6). This moisture variation results from varying grain size distribution in the tailing layers. It was observed that layers with significantly higher fraction of finer particles (1_2-6 and 1_2-11) had higher moisture content than the layers with relatively coarser particles. In order to illustrate particle size variation with depths, the determined $D_{80}$ values for the various layers of the drill core were plotted against the depth, as shown in Figure 7.

Layer 1_2-2, located between 87 and $144 \mathrm{~cm}$ depth, was significantly coarser $\left(\mathrm{D}_{80}=681 \mu \mathrm{m}\right)$. On the other hand, layers 1_2-6 and 1_2-11 at 303 and $483 \mathrm{~cm}$ depth were significantly finer, with $\mathrm{D}_{80}$ values of 259 and $227 \mu \mathrm{m}$, respectively. This variation in grain size distribution with depth is the first indication of the presence of different geometallurgical units, which may have different metallurgical performances [8], and thus need to be characterized. The variability would likely have an effect on the choice of methods to be considered for reprocessing, such as further grinding to liberate minerals of interest that may be locked up in the coarse particles, as observed with optical microscopy. 


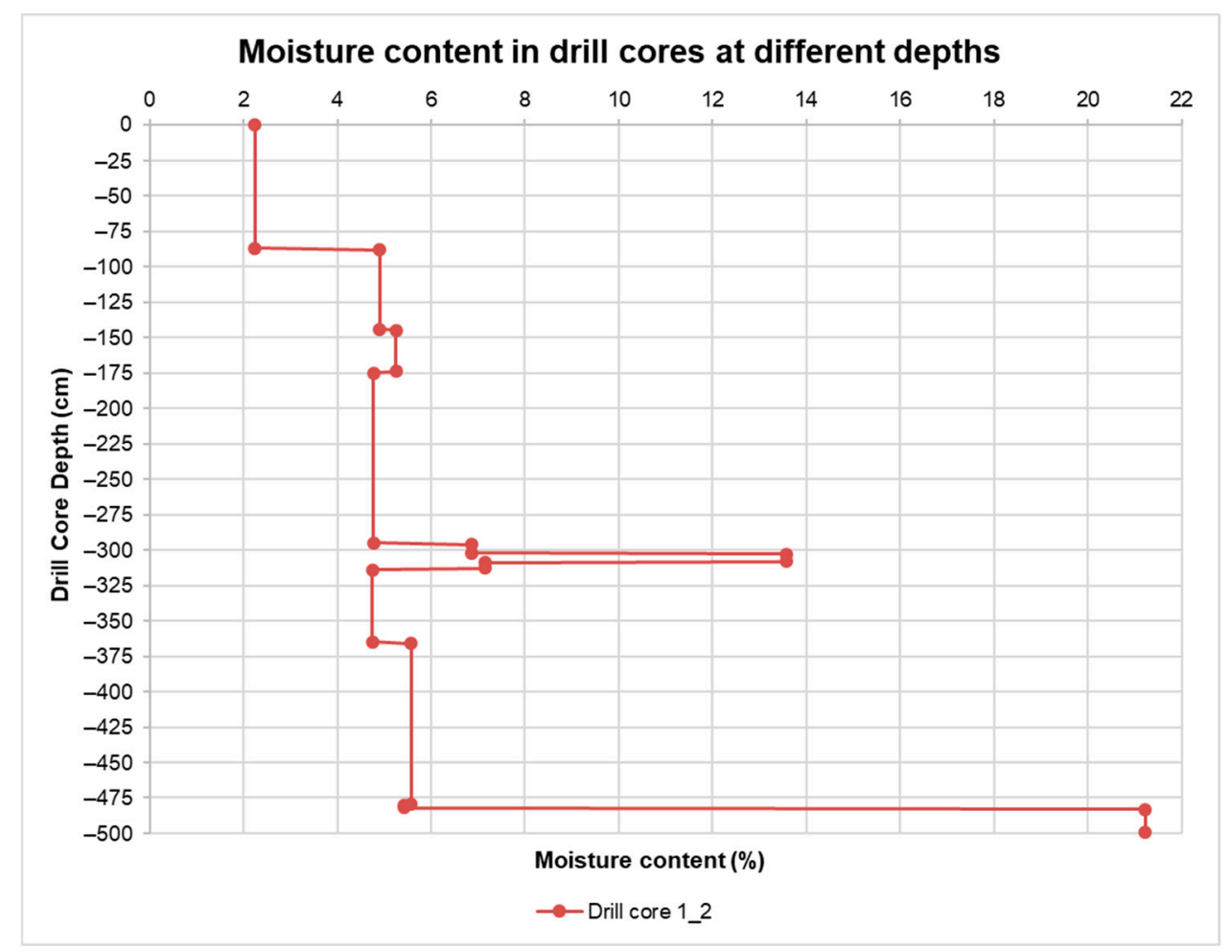

Figure 6. Moisture content variation with depths.

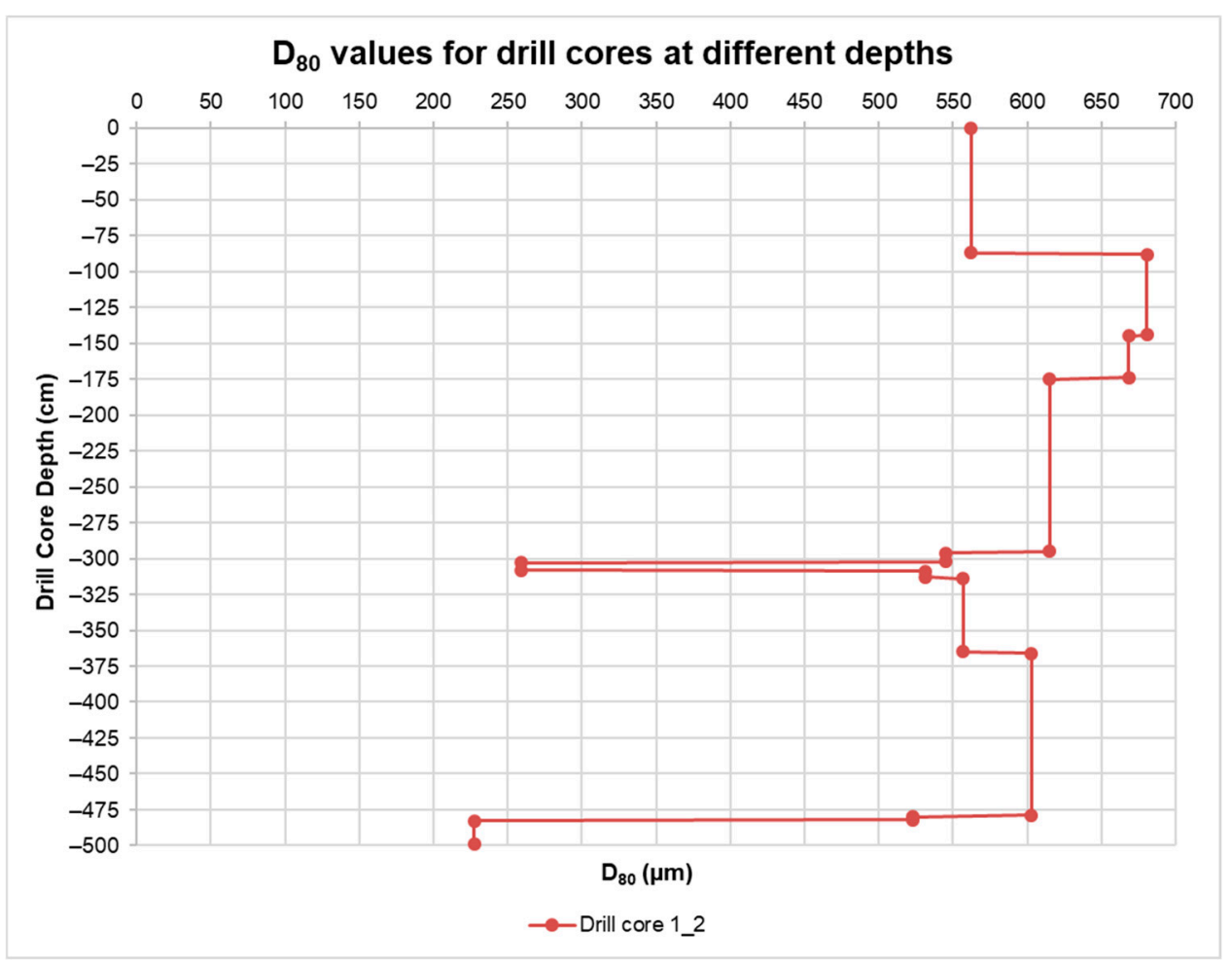

Figure 7. Variation of $D_{80}$ values with depth. This graph type depicts the observed abrupt changes in the drill core layers.

The -600 to $+297 \mu \mathrm{m}$ and -297 to $+149 \mu \mathrm{m}$ were the dominating particle size fractions, except the two layers with higher proportions of finer fractions mentioned above (Figure 8). This variation in 
particle size is indicative of varying process parameters, such as grinding size and/or changes in the mineralogy during the production period of 1936 to 1963.

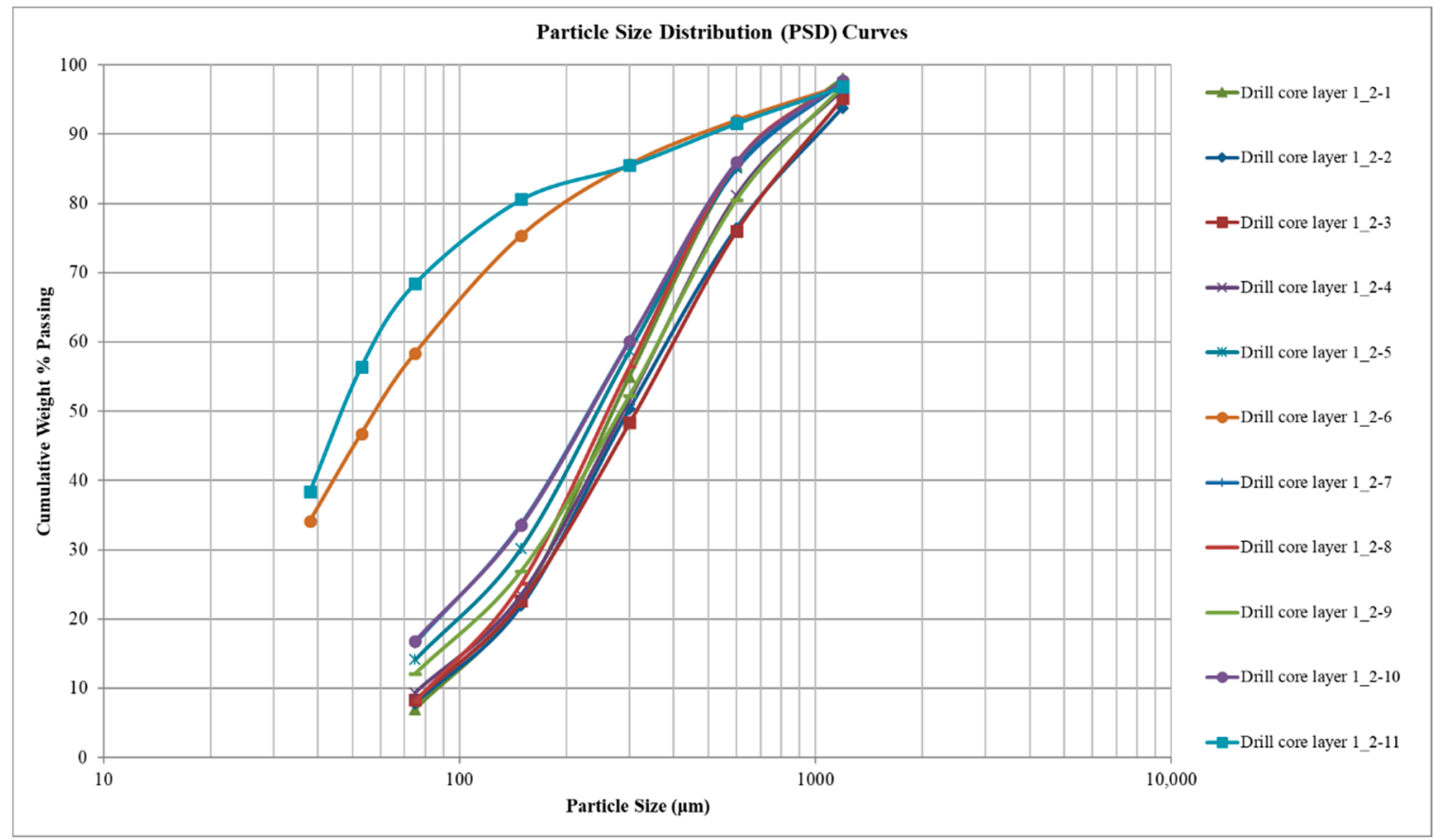

Figure 8. PSD curves for the 11 drill core layers.

The chemical composition of the various particle size fractions was also determined. The major components were $\mathrm{SiO}_{2}, \mathrm{Al}_{2} \mathrm{O}_{3}, \mathrm{CaO}$, and $\mathrm{Fe}_{2} \mathrm{O}_{3}$, while $\mathrm{W}, \mathrm{Cu}, \mathrm{S}, \mathrm{Sn}, \mathrm{Zn}, \mathrm{Be}$, and $\mathrm{Bi}$ were the main trace elements. From the elemental concentrations in the particle size fractions, weighted average concentrations in each layer were determined and subsequently calculated for the entire drill core.

Figure 9 illustrates elemental concentrations and mass distributions for layer 1_2-4 as an example, which is the layer with the highest mass distribution of tailings in this drill core (compare Figure 3). Considering the drill core as a whole, $\mathrm{W}$ and $\mathrm{Cu}$, as the main metals of interest, were observed to have high concentrations of $2329 \mathrm{mg} / \mathrm{kg}$ and $1427 \mathrm{mg} / \mathrm{kg}$, respectively, in the fine $(<75 \mu \mathrm{m})$ particle size fraction. All elements were high in the dominating particle size fractions mentioned earlier. Therefore, for purposes of reprocessing these HT, additional steps for ensuring sufficient mineral liberation need to be considered for such coarse tailings particles.
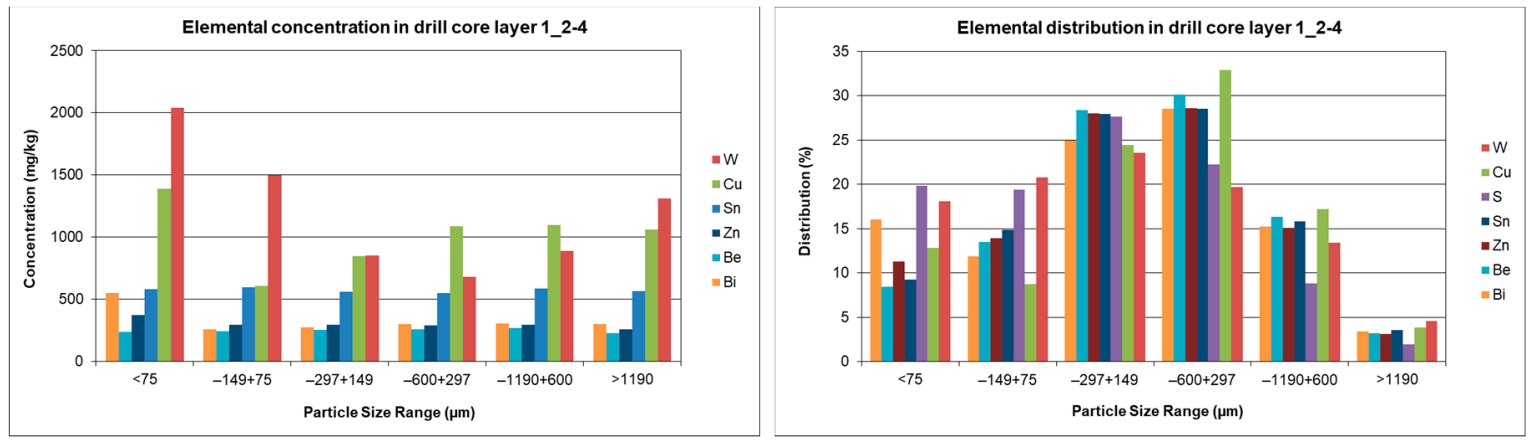

Figure 9. Elemental concentrations (left) and mass distributions (right) in the six particle size fractions for layer 1_2-4. 
The chemical composition of the drill core was also varying with depth. The highest $\mathrm{WO}_{3}$ concentration was $0.22 \mathrm{wt}$.\% in layer 1_2-2 (between 87 and $144 \mathrm{~cm}$ ), as shown in Figure 10. Since this was the layer with the coarsest tailings particles, it means that during the concentration processes shown in Figure 1a, most of the scheelite mineral particles should have been lost to these tailings as non-liberated particles. The highest $\mathrm{Cu}$ concentration was $1147 \mathrm{mg} / \mathrm{kg}$ in layer 1_2-8, at a much deeper depth between 313 and $365 \mathrm{~cm}$. However, it is important to know the mass distribution of metals in the layers, because the concentrations may be high but the actual quantities would be small when the total metal content in the drill core is considered. Therefore, the mass distribution for each element in the layers was calculated as a percentage of the total elemental content in the drill core. Figure 11 shows the $\mathrm{WO}_{3}$ and $\mathrm{Cu}$ mass distributions in the drill core. It shows that much of the $\mathrm{WO}_{3}$ and $\mathrm{Cu}$ was contained at the depth between 174 and $295 \mathrm{~cm}$, which contain $32 \mathrm{wt} . \%$ of the total $\mathrm{WO}_{3}$ and 29 wt. $\%$ of the total $\mathrm{Cu}$.
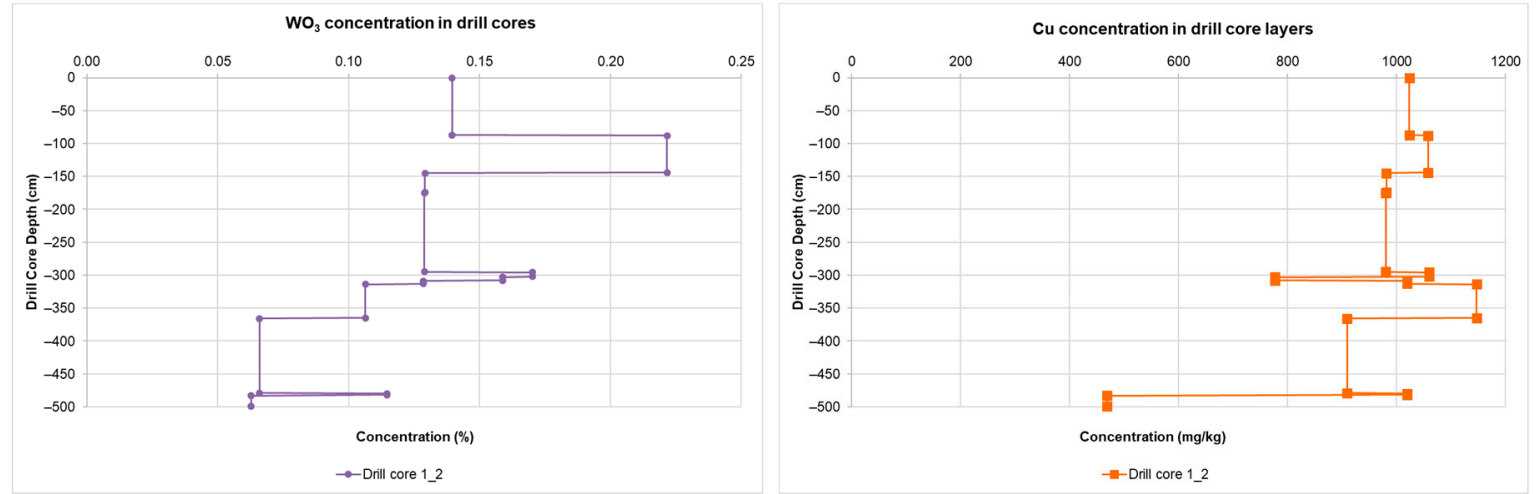

Figure 10. $\mathrm{WO}_{3}$ (left) and $\mathrm{Cu}$ (right) concentrations in the 11 drill core layers.
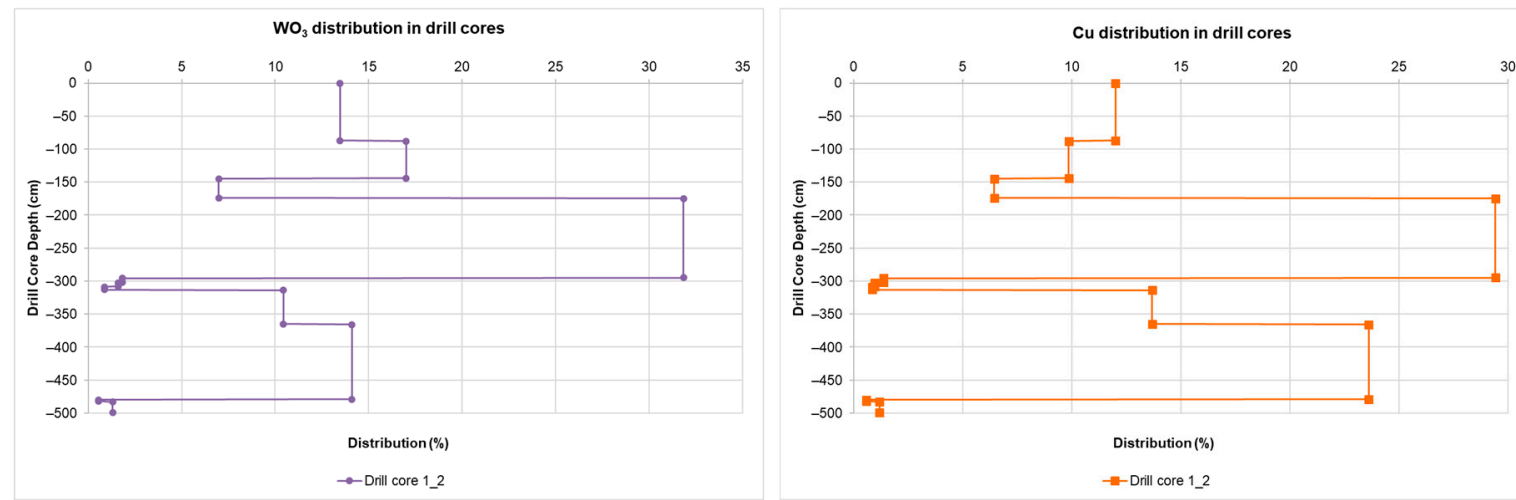

Figure 11. $\mathrm{WO}_{3}$ (left) and $\mathrm{Cu}$ (right) mass distributions in the 11 drill core layers.

Since these tailings have been stored in this repository for a long period, sulphur depletion due to oxidation was expected, with the depletion decreasing from top to bottom-even though this would also depend on other factors such as particle size and initial quantity. Therefore, both the concentration and mass distribution of sulphur in each layer was analyzed. The highest $\mathrm{S}$ concentration was also in layer 1_2-2 at 1.85\%, as shown in Figure 12 (left). However, with regard to mass distribution, it was observed that much of the $S$ was contained in layer 1_2-4 at the depth between 174 and $295 \mathrm{~cm}$, with 28 wt. $\%$ of the total S.

Observing the $\mathrm{S}$ depletion trend for the drill core according to Figure 12 (right), there would be three possible main deposition and oxidation periods where $S$ is seen to have a significant stepwise increase in depth; the first being for the depth $296-483 \mathrm{~cm}$, second 145-295 cm, and third 0-144 cm. Based on the alteration index of minerals and $\mathrm{pH} / \mathrm{EC}$ in the tailings, the upper section-oxidized acidic zone ( $\mathrm{pH}<5.5$ - - showed that pyrrhotite was completely replaced by HFOs, calcite depleted, and 
occasional yellow rims around scheelite grains [17]. These trends also show possible mineralogical variations with regard to sulphur content over the production period of 1936 to 1963.
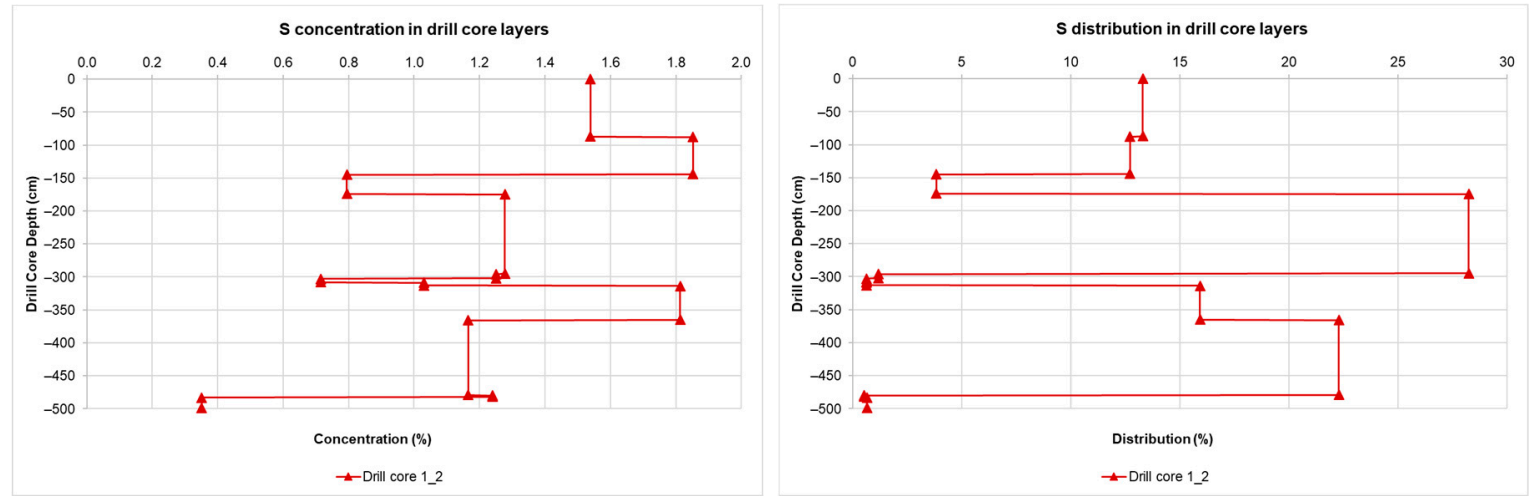

Figure 12. Sulphur concentration (left) and mass distribution (right) in the 11 drill core layers.

Table 4 summarizes the concentrations of the seven main elements in the 11 layers and the weighted averages in the drill core. The variations in the elemental concentrations and distributions at different depths would have an effect on the grades and recoveries of the concentrates that may be produced from the reprocessing of the HT. Consequently, process parameters would need to be varied depending on what depth the tailings are obtained. For instance, in order to recover much of the $\mathrm{W}$ and $\mathrm{Cu}$, the tailings at deeper depths (below $174 \mathrm{~cm}$ ) must be treated. Blending of tailings before reprocessing may also be necessary for process and product optimization.

Table 4. Elemental concentrations in the layers and the drill core as a whole.

\begin{tabular}{cccccccc}
\hline Sample & $\begin{array}{c}\mathbf{W O}_{\mathbf{3}} \\
\mathbf{( \% )}\end{array}$ & $\begin{array}{c}\mathbf{C u} \\
(\mathbf{m g} / \mathbf{k g})\end{array}$ & $\begin{array}{c}\mathbf{S} \\
\mathbf{( \% )}\end{array}$ & $\begin{array}{c}\mathbf{S n} \\
\mathbf{( m g / k g )}\end{array}$ & $\begin{array}{c}\mathbf{Z n} \\
\mathbf{( m g / k g )}\end{array}$ & $\begin{array}{c}\mathbf{B e} \\
\mathbf{( m g / k g )}\end{array}$ & $\begin{array}{c}\mathbf{B i} \\
(\mathbf{m g} / \mathbf{k g})\end{array}$ \\
\hline Layer 1_2-1 & 0.14 & 1024 & 1.54 & 554 & 311 & 267 & 454 \\
Layer 1_2-2 & 0.22 & 1058 & 1.85 & 560 & 313 & 289 & 460 \\
Layer 1_2-3 & 0.13 & 982 & 0.79 & 516 & 333 & 278 & 342 \\
Layer 1_2-4 & 0.13 & 980 & 1.28 & 569 & 300 & 254 & 311 \\
Layer 1_2-5 & 0.17 & 1060 & 1.25 & 590 & 305 & 249 & 298 \\
Layer 1_2-6 & 0.16 & 777 & 0.72 & 709 & 309 & 239 & 286 \\
Layer 1_2-7 & 0.13 & 1020 & 1.03 & 611 & 303 & 253 & 302 \\
Layer 1_2-8 & 0.11 & 1147 & 1.81 & 528 & 313 & 237 & 418 \\
Layer 1_2-9 & 0.07 & 910 & 1.17 & 600 & 102 & 204 & 454 \\
Layer 1_2-10 & 0.11 & 1020 & 1.24 & 562 & 326 & 239 & 439 \\
Layer 1_2-11 & 0.06 & 469 & 0.35 & 150 & 89 & 63.2 & 202 \\
Drill core 1_2 & 0.12 & 981 & 1.33 & 558 & 251 & 241 & 390 \\
\hline
\end{tabular}

Under the optical microscope, scheelite particles were observed in normal light and with a blue filter (Figure 13). The scheelite particles in the polished samples were both fine and coarse, as well as liberated and non-liberated, meaning that mineral liberation analysis would be essential in order to develop effective separation methods. Some particles showed rims, which were identified as hydrous ferric oxides [20]; hence, the recovery of such scheelite mineral particles may be hindered in processes like flotation where reagents need to have contact with the mineral particle, and also in magnetic separation where scheelite would end up being pulled to the paramagnetic fraction. Hence, pre-treatment methods such as scrubbing may be required. The main minerals in which the main elements $\mathrm{W}, \mathrm{Cu}, \mathrm{S}, \mathrm{Sn}, \mathrm{Zn}, \mathrm{Be}$, $\mathrm{Bi}$, and $\mathrm{F}$ were contained were scheelite, chalcopyrite, pyrrhotite, cassiterite, danalite (both $\mathrm{Zn}$ and $\mathrm{Be}$ ), bismuthinite, and fluorspar, respectively $[20,24]$ 

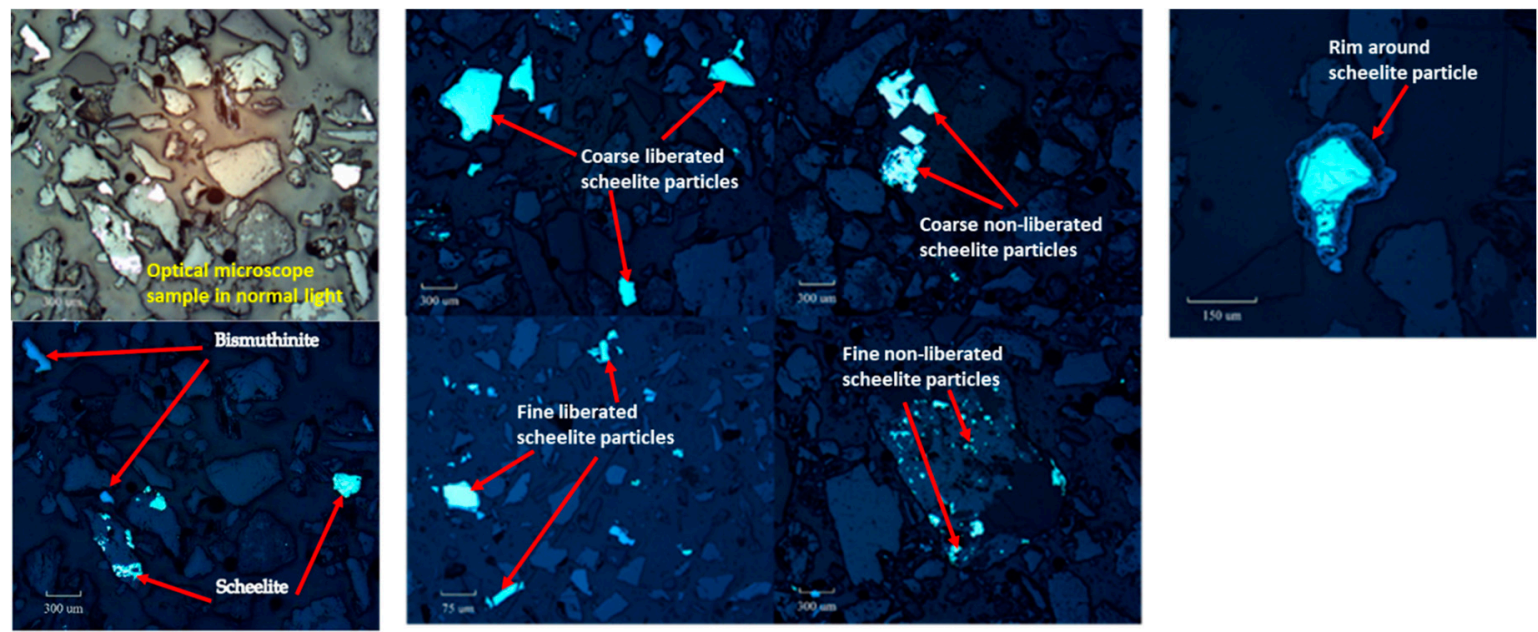

Figure 13. Micrographs of tailings showing scheelite texture and liberation in various particle size fractions, and an example of a rim around a scheelite particle.

The particle and compositional characterization of these historical tailings based on the analyzed drill core revealed significant vertical variations in the repository. For this HT repository, the prediction of metallurgical performance based on geometallurgical units would be defined first from the drill core layers perspective. This approach of using the repository layers as samples for metallurgical test work helps to avert technical errors that arise from the use of composite samples, which may not sufficiently represent the repository [11]. The metallurgical performance of the individual drill core layers provides an effective way of assessing their eventual effect on composite samples. For repository locations with several different layers, such as $1 \_2$, blending of the layers would be inevitable because of the insufficient thickness of some of the layers. The variability would unavoidably affect the choice of the reprocessing methods and the elemental/mineralogical composition of the products $[8,11]$.

\subsection{Processing Properties}

The Yxsjöberg tailings are fine particles $(-600$ to $+38 \mu \mathrm{m})$ with high-density valuable minerals such as scheelite $\left(6.01 \mathrm{~g} / \mathrm{cm}^{3}\right)$ and bismuthinite $\left(7 \mathrm{~g} / \mathrm{cm}^{3}\right)$, and low-density gangue minerals such as quartz $\left(2.62 \mathrm{~g} / \mathrm{cm}^{3}\right)$ and calcite $\left(2.71 \mathrm{~g} / \mathrm{cm}^{3}\right)$ [25]. Therefore, enhanced gravity separation where a centrifugal force is applied to enhance the differential settling velocities between heavy and light particles $(-80,000$ to $+10 \mu \mathrm{m})$ would be appropriate for these HT; thus, a Knelson concentrator was used [19]. The tailings have a high sulphur concentration, and the sulphur occurs mainly in pyrrhotite, which is weakly-to-strongly magnetic. Magnetite, a ferromagnetic mineral, is also present, and as such, LIMS and HIMS were also considered as plausible processing methods. The magnetic separation would enhance the separation of minerals like scheelite and chalcopyrite from pyrrhotite, which is the main Fe-sulphide mineral in the tailings responsible for AMD [20].

\subsubsection{Magnetic Separation Tests}

The two samples from layers 1_2-4 and 1_2-8 were used separately in magnetic separation tests. The three products from the magnetic separation, namely, ferromagnetic, paramagnetic, and non-magnetic fractions, had significant visual (color) differences, with the non-magnetic fraction dominated by the orange-, brown-, and white-colored minerals. Based on the knowledge of minerals known to be present in the samples and using EMC, the light-colored minerals in the non-magnetic fraction were identified to be mainly albite, fluorspar, calcite, scheelite, and biotite.

The desired outcome of the magnetic separation test was to have the valuable minerals (scheelite, fluorspar, and chalcopyrite) in the non-magnetic fraction of the HIMS, but the mass recovery to this fraction for both samples was very low, with the highest amount being only $9.2 \mathrm{wt}$.\% from layer 1_2-8. 
From Figure 14 and Table 5, it is observed that much of the $\mathrm{W}$ and $\mathrm{Cu}$ ended up in the paramagnetic fraction for both layers; meaning the separation of scheelite and chalcopyrite was not achieved as desired. This could be due to the insufficient liberation of scheelite and chalcopyrite minerals from pyrrhotite and/or to liberated small particles being entrapped and entrained by the paramagnetic particles. The insufficient liberation of scheelite was confirmed by the higher $\mathrm{W}$ recovery of $83.6 \mathrm{wt} . \%$ in the paramagnetic fraction, from the less coarse layer 1_2-8 which had more $\mathrm{W}$ retained in the -600 to $+297 \mu \mathrm{m}$ fraction as compared to layer 1_2-4. The paramagnetic fraction had the highest mass recoveries with $87.3 \mathrm{wt} . \%$ for layer $1 \_2-4$ and $85.8 \mathrm{wt} . \%$ for layer $1 \_2-8$, and based on EMC, approximately $40 \mathrm{wt} . \%$ and $30 \mathrm{wt} . \%$ of pyrrhotite was in this fraction, respectively, indicating that a high amount of pyrrhotite was ferromagnetic. Sulphur was mostly recovered in the ferromagnetic and paramagnetic fractions with only $1.0 \mathrm{wt} . \%$ in the non-magnetic fraction of layer 1_2-8, meaning that pyrrhotite, the main Fe-sulphide mineral in the tailings and responsible for AMD, was retained in the desired magnetic fractions of the LIMS and HIMS. For both layers, the mass recovered by the LIMS was very low, with the highest amount being only $5.0 \mathrm{wt}$.\% from layer 1_2-8. This could indicate a low amount of the ferromagnetic mineral magnetite in the tailings. But considering the high recovery of $\mathrm{Fe}_{2} \mathrm{O}_{3}$ in the paramagnetic fraction, it could also mean that a larger amount of magnetite was locked up with pyrrhotite and/or other non-paramagnetic minerals, such as cassiterite, danalite, bismuthinite, fluorspar, calcite, and quartz.
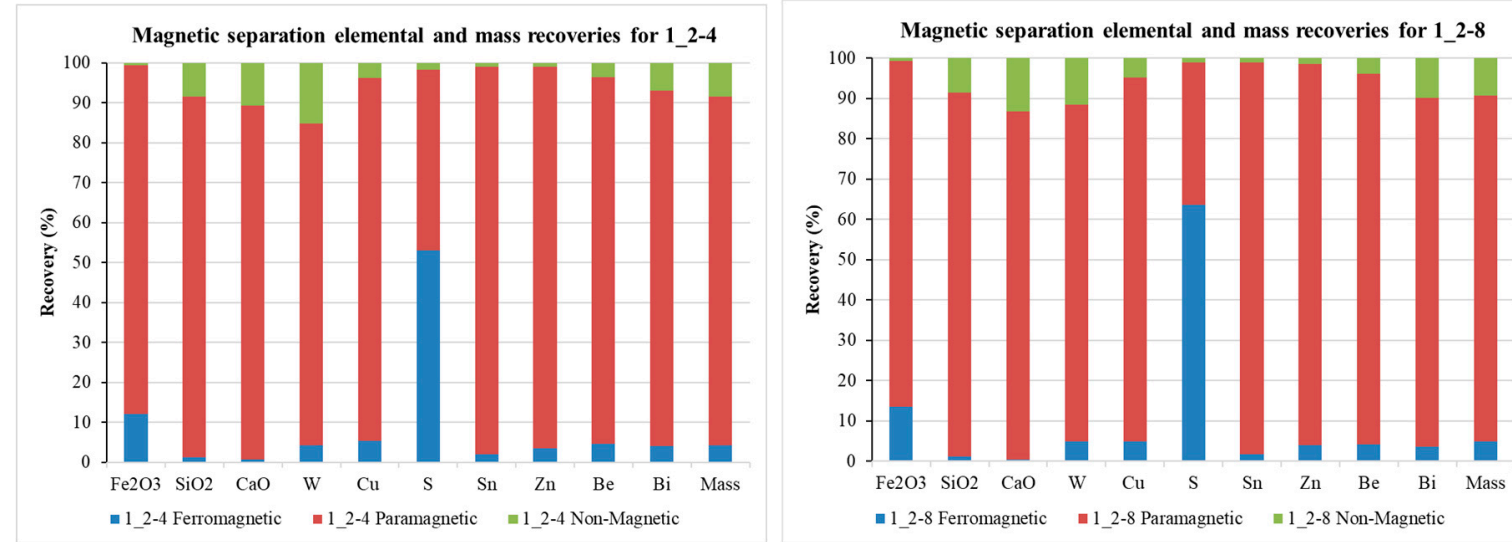

Figure 14. Magnetic separation elemental and mass recoveries.

Table 5. Products balance for magnetic separation.

\begin{tabular}{lcccccccc}
\hline & \multicolumn{2}{c}{ Weight } & \multicolumn{2}{c}{ Assays $(\mathbf{m g} / \mathbf{k g})$} & \multicolumn{2}{c}{ Contents $\mathbf{( g )}$} & \multicolumn{2}{c}{ Distribution (\%) } \\
\hline \multicolumn{1}{c}{ Product } & gram & $\mathbf{\%}$ & $\mathbf{W}$ & $\mathbf{S}$ & $\mathbf{W}$ & $\mathbf{S}$ & $\mathbf{W}$ & S \\
\hline 1_2-4 Ferromagnetic & 8.19 & 4.21 & 872 & 144,000 & 0.01 & 1.18 & 4.2 & 53.1 \\
1_2-4 Paramagnetic & 169.66 & 87.30 & 800 & 5920 & 0.14 & 1.00 & 80.6 & 45.2 \\
1_2-4 Non-Magnetic & 16.50 & 8.49 & 1550 & 2270 & 0.03 & 0.04 & 15.2 & 1.7 \\
1_2-4_Calculated Feed $(+75 \mu \mathrm{m})$ & 194.35 & 100.00 & 867 & 11,429 & 0.17 & 2.22 & 100.0 & 100.0 \\
1_2-8 Ferromagnetic & 8.64 & 4.98 & 685 & 222,000 & 0.01 & 1.92 & 4.9 & 63.5 \\
1_2-8 Paramagnetic & 148.97 & 85.82 & 683 & 7180 & 0.10 & 1.07 & 83.6 & 35.4 \\
1_2-8 Non-Magnetic & 15.98 & 9.21 & 877 & 1930 & 0.01 & 0.03 & 11.5 & 1.0 \\
1_2-8_Calculated Feed $(+75 \mu \mathrm{m})$ & 173.59 & 100.00 & 701 & 17,389 & 0.12 & 3.02 & 100.0 & 100.0 \\
\hline
\end{tabular}

Assessing the particle sizes in the products in relation to what was in the feed, it was observed that $97 \mathrm{wt} . \%$ of the -600 to $+297 \mu \mathrm{m}$ particles, being the most abundant in these HT, were distributed to the paramagnetic fraction (Figure 15). This confirms that the minerals of interest, like scheelite, need to be further liberated from this particle size fraction in order to improve mineral separation by magnetic separation. 


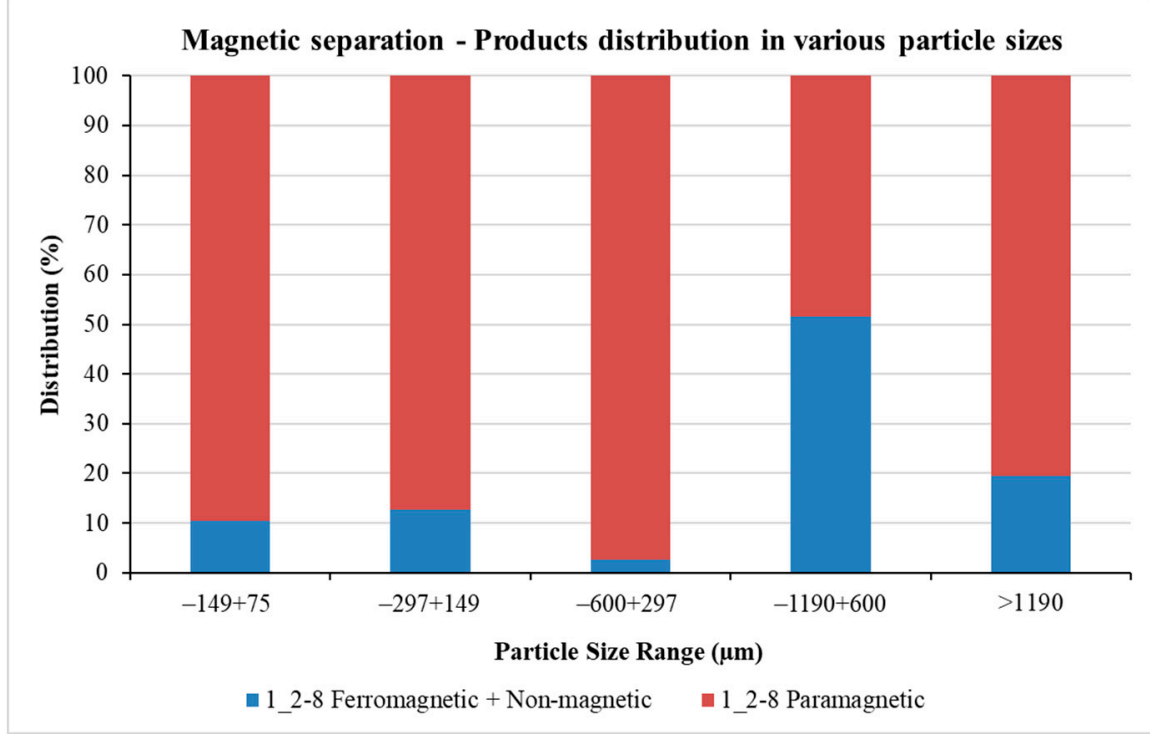

Figure 15. Magnetic separation products distribution over particle size ranges.

\subsubsection{Gravity Separation Tests}

The two layers (1_2-1 and 1_2-8) of drill core 1_2 were individually used for gravity separation tests with the Knelson concentrator, with two separation cycles for each sample. For comparison in metallurgical performance, these samples were quite similar in terms of mass distribution in the core, but slightly different in chemical composition, grain size, and exposure to weathering. The recovery of scheelite in each cycle product was assessed by the amount of W (Figure 16). It was observed that recovery of $\mathrm{W}$ in the concentrates was decreasing with an increasing number of separation cycles, with the highest recovery being $60.6 \mathrm{wt} . \%$ in concentrate 1 of layer 1_2-1. The decrease in $W$ recovery with increasing number of separation cycles was due to the decreasing amount of dense and coarse particles that contain $\mathrm{W}$. In this regard, comparison between the two layers showed a higher $\mathrm{W}$ recovery in concentrate 1 for layer 1_2-1, which was coarser with higher W content than layer 1_2-8. This can be seen in the products mass balance calculations given in Table 6 .
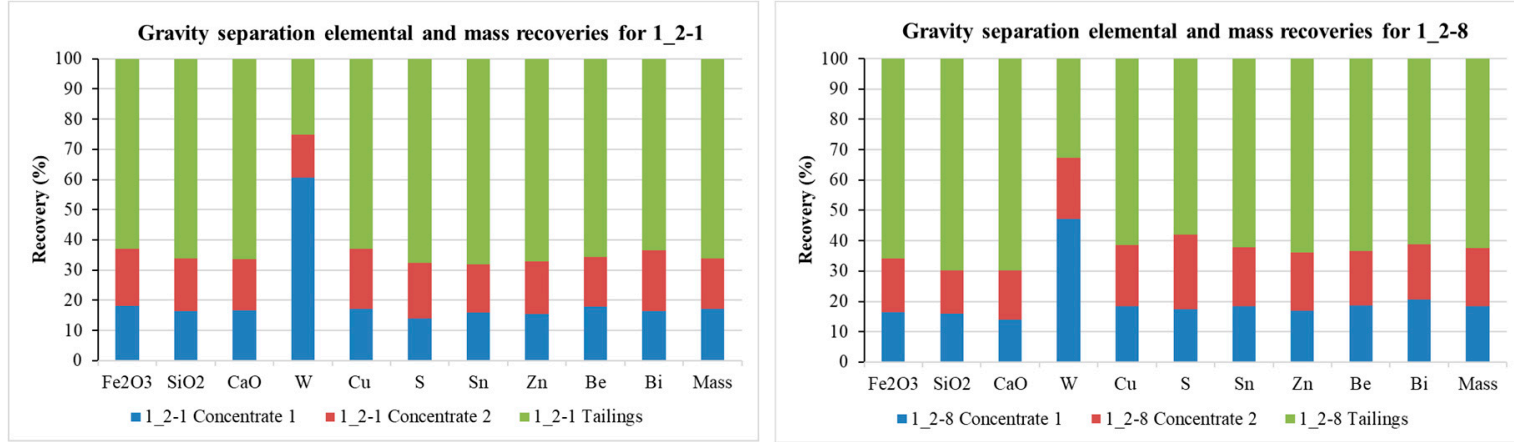

Figure 16. Gravity separation (Knelson concentrator) elemental and mass recoveries.

Even though the recovery of scheelite was significantly favorable with this enhanced gravity separation, it is important to look at the selectivity, i.e., its separation from the other minerals. From Figure 16, it is observed that in both samples, other than $\mathrm{W}$, at least $30 \mathrm{wt} . \%$ of each main element was also recovered to the concentrate fraction. This means that quartz $\left(2.62 \mathrm{~g} / \mathrm{cm}^{3}\right)$, fluorspar $\left(3.13 \mathrm{~g} / \mathrm{cm}^{3}\right)$, calcite $\left(2.71 \mathrm{~g} / \mathrm{cm}^{3}\right)$, chalcopyrite $\left(4.19 \mathrm{~g} / \mathrm{cm}^{3}\right)$, pyrrhotite $\left(4.61 \mathrm{~g} / \mathrm{cm}^{3}\right)$, and danalite $\left(3.43 \mathrm{~g} / \mathrm{cm}^{3}\right)$ were not fully separated from scheelite, despite having much lower mineral densities than scheelite $\left(6.01 \mathrm{~g} / \mathrm{cm}^{3}\right)$. Considering the coarseness of the particles in these samples, the insufficient mineral separation would 
be attributed to the insufficient liberation of the mineral particles. With regard to the tailing fraction, $\mathrm{W}$ distribution was considerably high at $32.7 \mathrm{wt} . \%$ in layer $1 \_2-8$, which is an indication of relatively high scheelite distribution into the fine fractions. The scheelite particles may be liberated in the fine fractions but would still end up in the tailings because of the preferential concentration of coarser particles due to their combined effect of size and density, which are important in enhanced gravity separation.

Table 6. Products mass balance for gravity concentration products using Knelson concentrator.

\begin{tabular}{lccccc}
\hline \multirow{2}{*}{ Product } & \multicolumn{2}{c}{ Weight } & Assays $(\mathbf{m g} / \mathbf{k g})$ & Contents $\mathbf{( g )}$ & \multicolumn{2}{c}{ Distribution (\%) } \\
\cline { 2 - 6 } & gram & \% & W & W & W \\
\hline 1_2-1 Concentrate 1 & 88.88 & 17.05 & 4190 & 0.37 & 60.6 \\
1_2-1 Concentrate 2 & 87.71 & 16.82 & 992 & 0.09 & 14.2 \\
1_2-1 Tailings & 344.83 & 66.13 & 449 & 0.15 & 25.2 \\
1_2-1_Actual Feed $(-600 \mu \mathrm{m})$ & 521.42 & 100.00 & 1178 & 0.61 & 100.0 \\
\hline 1_2-8 Concentrate 1 & 92.56 & 18.53 & 1950 & 0.18 & 47.1 \\
1_2-8 Concentrate 2 & 95.61 & 19.14 & 813 & 0.08 & 20.3 \\
1_2-8 Tailings & 311.47 & 62.34 & 402 & 0.13 & 32.7 \\
1_2-8_Actual Feed $(-600 \mu \mathrm{m})$ & 499.64 & 100.00 & 767 & 0.38 & 100.0 \\
\hline
\end{tabular}

Using products distribution in various particle sizes to further assess the concentration process (Figure 17), it was confirmed that the dense coarser $(-600$ to $+297 \mu \mathrm{m})$ particles were distributed more to concentrate 1 than 2 , while the dense finer $(<75 \mu \mathrm{m})$ particles were higher in concentrate 2 than 1 . Therefore, in order to minimize $\mathrm{W}$ losses in the fines to the tailing fraction, the particle size range of the feed material to the Knelson concentrator must be narrow; otherwise, many concentration cycles would be needed to optimize the recovery. In this initial metallurgical test work, the feed particle size range was -600 to $+38 \mu \mathrm{m}$; however, for subsequent tests, division of this size range into narrower ones such as -600 to $+297 \mu \mathrm{m},-297$ to $+149 \mu \mathrm{m},-149$ to $+75 \mu \mathrm{m}$, and -75 to $+38 \mu \mathrm{m}$ should be considered in order to improve the recovery and separation efficiency [19].

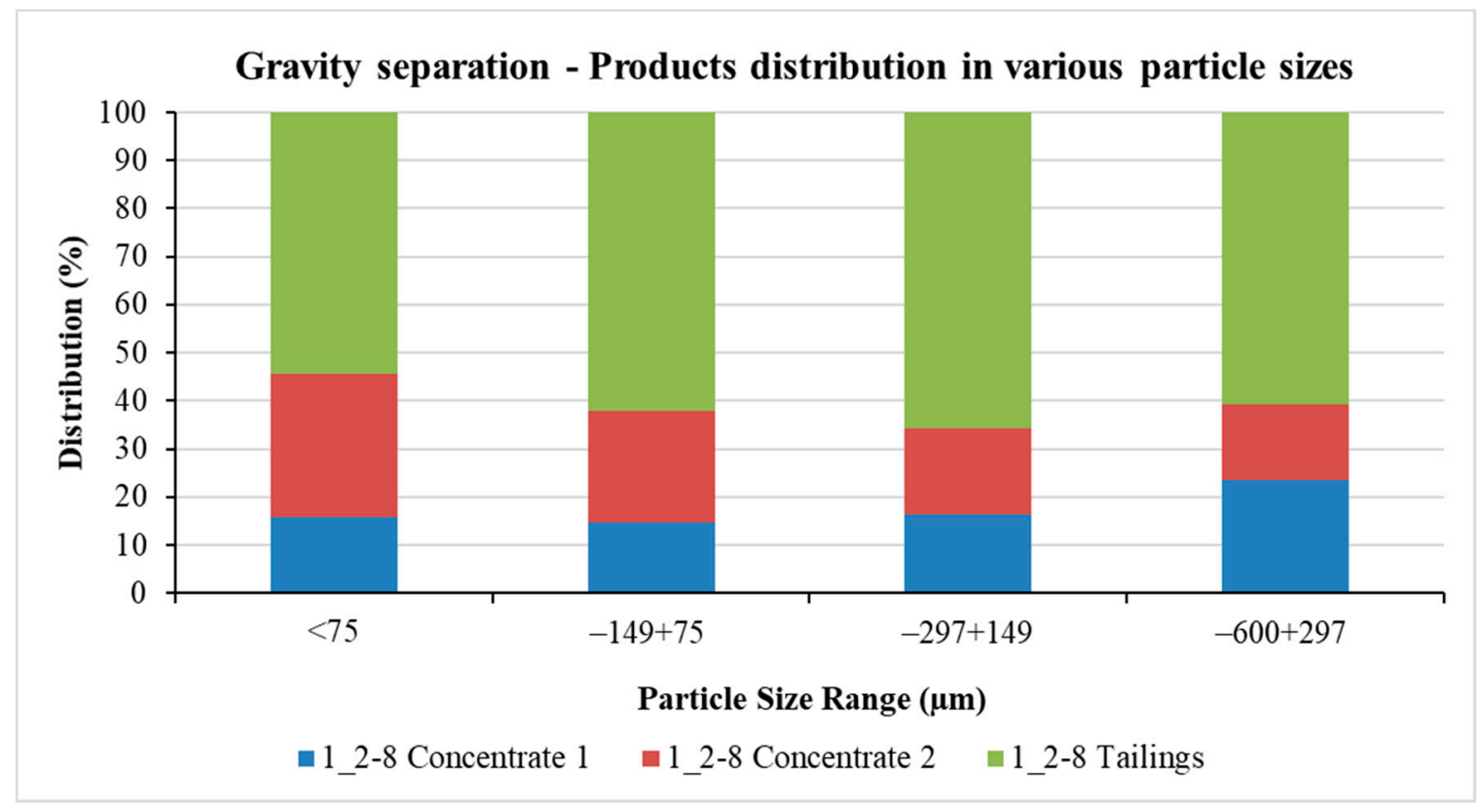

Figure 17. Knelson concentrator products distribution over particle size ranges.

\subsubsection{Proposed Process Flowsheet}

Based on the preliminary results of the physical and chemical characterization, as well as processing tests, a process flowsheet is proposed (Figure 18). Given the high deportment of mass and economic 
elements into the coarser particle size fractions $(-600$ to $+149 \mu \mathrm{m})$, classification to separate the coarser tailings from the finer ones would be the first step. The threshold for such a classification should be $<75 \mu \mathrm{m}$ because, from optical microscopy and SEM observations, scheelite particles in this size fraction are liberated. Also, during gravity separation, much of the $<75 \mu \mathrm{m}$ ended up in the tailing product; hence, there is a need for prior separation. Basically, scheelite recovery from this particle size fraction would be best through froth flotation [26]. For the tailing fraction $>75 \mu \mathrm{m}$, the issue of mineral liberation is evident; hence, regrinding will be required. However, more studies need to be done to determine the optimal mineral liberation size for scheelite in the tailings so that generation of ultrafine particles is minimized. With sufficient mineral liberation, having magnetic separation before gravity separation enhances the separation of magnetite (in addition to pyrrhotite) from scheelite; magnetite density $\left(5.15 \mathrm{~g} / \mathrm{cm}^{3}\right)$ is close to that of scheelite $\left(6.01 \mathrm{~g} / \mathrm{cm}^{3}\right)$ [25]; hence, their separation with gravity method may not be efficient. Therefore, gravity separation would be applied to the non-magnetic product of magnetic separation.

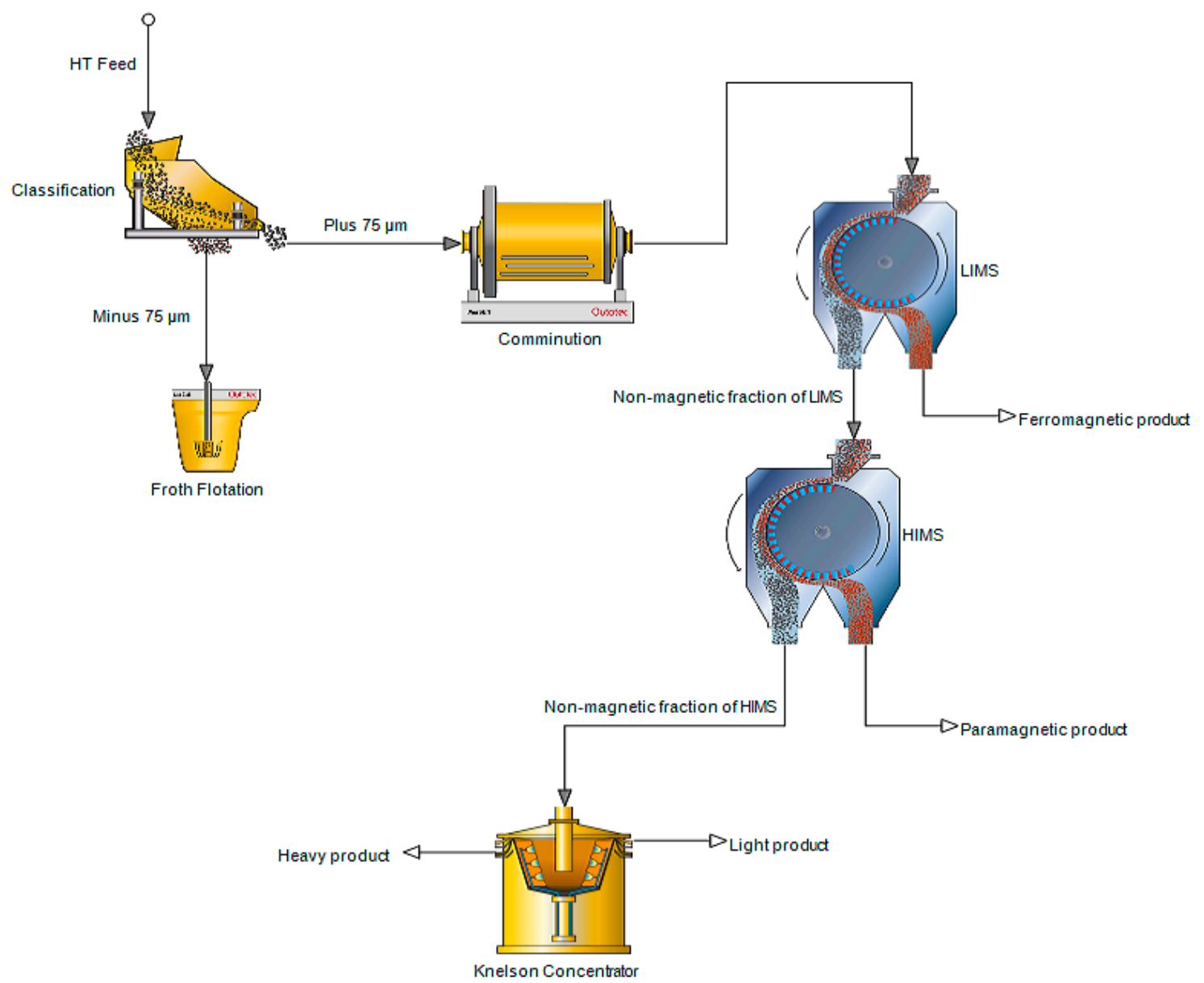

Figure 18. Preliminary process flowsheet proposed for separation of valuable minerals from the Yxsjöberg historical tailings (HT).

\subsection{Proposed Methodology for HT Reprocessing}

Based on the preliminary study presented in this paper and future work foresight, a methodology for reprocessing the Yxsjöberg HT is proposed (Figure 19). The methodology is divided into three main steps, namely, TSF characterization, metallurgical test work, and process design and analysis. Each of these steps has defined tasks, which represent sub-steps and methods to be undertaken in each step, e.g., characterization of tailings is a sub-step in the TSF characterization category, but it also has sub-steps 
and methods as shown in Figure 4. The methodology is preliminary because, with further investigations on the tailings, sub-steps that are more specific may be added to the three methodology steps.

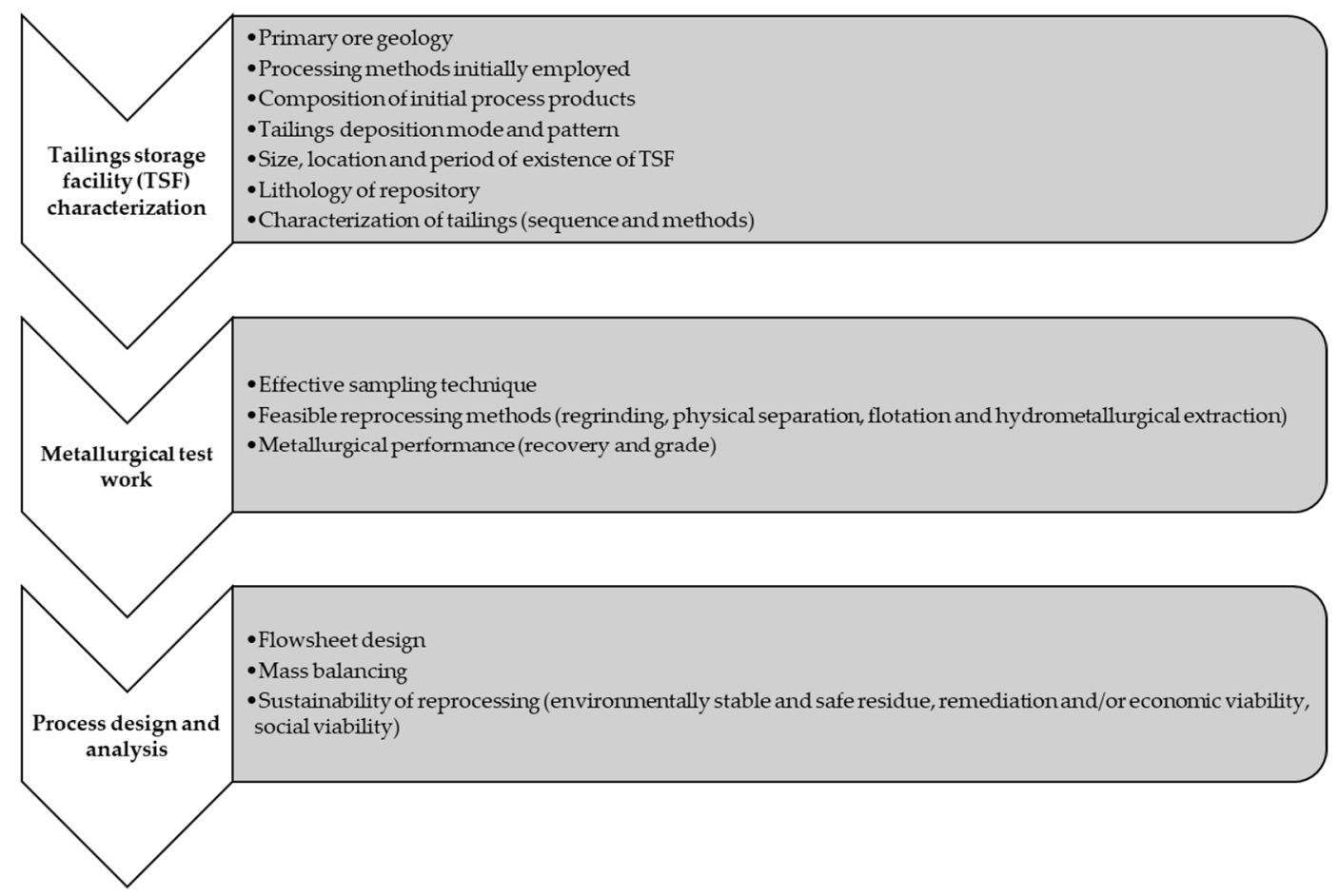

Figure 19. Preliminary methodology proposed for the reprocessing of Yxsjöberg HT.

\section{Conclusions}

In this study, a preliminary process flowsheet and a methodology for reprocessing the historical tailings from the historical Yxsjöberg tungsten mine has been proposed. The following are the main findings and conclusions:

- The tailings in the repository are vertically stratified, with layers having significant variation in particle size distribution and composition. The variation reflects variation in initial processing parameters (e.g., milling) and/or in mineralogy of the original run-of-mine ore. The chemical composition is high in the coarser particle size fraction range -600 to $+149 \mu \mathrm{m}$. With regard to texture and liberation, scheelite particles are both fine- and coarse-grained, liberated and non-liberated, meaning that mineral liberation analysis will be essential in the development of effective separation methods.

- $\mathrm{W}, \mathrm{Cu}, \mathrm{S}, \mathrm{Sn}, \mathrm{Zn}, \mathrm{Be}, \mathrm{Bi}$, and $\mathrm{F}$ are hosted mainly in scheelite, chalcopyrite, pyrrhotite, cassiterite, danalite (both $\mathrm{Zn}$ and Be), bismuthinite, and fluorspar, respectively. $\mathrm{W}$ and $\mathrm{Cu}$ are the metals of interest, and their highest concentrations are $0.22 \mathrm{wt} . \% \mathrm{WO}_{3}$ and $0.11 \mathrm{wt} . \% \mathrm{Cu}$, and averages are $0.12 \%$ and $0.1 \%$, respectively.

- Sulphur was mostly recovered in the ferromagnetic and paramagnetic fractions, with only $1.0 \mathrm{wt} . \%$ in the non-magnetic fraction, meaning pyrrhotite, the main Fe-sulphide mineral in the HT responsible for AMD, separated to the desired magnetic fractions of the LIMS and HIMS.

- The recovery of scheelite was significantly favorable with enhanced gravity separation using the Knelson concentrator, with the highest $\mathrm{W}$ recovery of $60.6 \mathrm{wt} . \%$.

\section{Future Work}

Since these characterization and processing findings only represent one location in the TSF, further geometallurgical studies are planned for samples from different locations, so that geometallurgical 
units can be defined within the entire TSF. Additionally, quantitative mineralogical studies of the processing products are required in order to ascertain that minerals of economic interest and minerals of environmental concern in the tailings are separated as desired. The proposed process flowsheet will require further refinement as the processes become more defined and optimized, for instance, the sequence of minerals to be floated, and additional classification after comminution.

Author Contributions: Conceptualization, J.R. and J.M.; methodology, J.M. and P.K.; validation, J.M. and P.K.; formal analysis, J.M. and P.K.; investigation, J.M. and P.K.; resources, J.R. and J.M.; data curation, J.M. and P.K.; writing —original draft preparation, J.M.; writing—review and editing, S.C.C. and J.R.; visualization, J.M.; supervision, S.C.C. and J.R.

Funding: This research was funded by Sweden's innovation agency VINNOVA, grant number 21506 631, within the ERA-NET Cofund on Raw Materials (ERA-MIN2).

Acknowledgments: The authors' sincere gratitude goes to the late Niclas Strandberg (AB Yxsjö Industriservice), who was the owner of the Yxsjöberg mining site, for his support of the project.

Conflicts of Interest: The authors declare no conflicts of interest. The funders had no role in the design of the study; in the collection, analyses, or interpretation of data; in the writing of the manuscript; or in the decision to publish the results.

\section{References}

1. Commission, E. Critical Raw Materials 2017. 2017. Available online: https://ec.europa.eu/growth/sectors/rawmaterials/specific-interest/critical_en (accessed on 31 October 2019).

2. British Geological Survey Risk List 2015-An update to the supply risk index for elements or element groups that are of economic value. Br. Geol. Surv. 2015, 1-2. Available online: http://www.bgs.ac.uk/mineralsuk/ statistics/risklist.html (accessed on 31 October 2019).

3. Leal-Ayala, D.R.; Allwood, J.M.; Petavratzi, E.; Brown, T.J.; Gunn, G. Mapping the global flow of tungsten to identify key material efficiency and supply security opportunities. Resour. Conserv. Recycl. 2015, 103, 19-28. [CrossRef]

4. Clemente, D.; Newling, P.; de Sousa, A.B.; LeJeune, G.; Barber, S.P.; Tucker, P. Reprocessing slimes tailings from a tungsten mine. Miner. Eng. 1993, 6, 831-839. [CrossRef]

5. Jamieson, H.E.; Walker, S.R.; Parsons, M.B. Mineralogical characterization of mine waste. Appl. Geochem. 2015, 57, 85-105. [CrossRef]

6. Brough, C.P.; Warrender, R.; Bowell, R.J.; Barnes, A.; Parbhakar-Fox, A. The process mineralogy of mine wastes. Miner. Eng. 2013, 52, 125-135. [CrossRef]

7. Lottermoser, B.G. Recycling, reuse and rehabilitation of mine wastes. Elements 2011, 7, 405-410. [CrossRef]

8. Lotter, N.O. Modern Process Mineralogy: An integrated multi-disciplined approach to flowsheeting. Miner. Eng. 2011, 24, 1229-1237. [CrossRef]

9. Lotter, N.O.; Baum, W.; Reeves, S.; Arrué, C.; Bradshaw, D.J. The business value of best practice process mineralogy. Miner. Eng. 2018, 116, 226-238. [CrossRef]

10. Whiteman, E.; Lotter, N.O.; Amos, S.R. Process mineralogy as a predictive tool for flowsheet design to advance the Kamoa project. Miner. Eng. 2016, 96-97, 185-193. [CrossRef]

11. Tungpalan, K.; Manlapig, E.; Andrusiewicz, M.; Keeney, L.; Wightman, E.; Edraki, M. An integrated approach of predicting metallurgical performance relating to variability in deposit characteristics. Miner. Eng. 2015, 71, 49-54. [CrossRef]

12. Lotter, N.O.; Oliveira, J.F.; Hannaford, A.L.; Amos, S.R. Flowsheet development for the Kamoa project-A case study. Miner. Eng. 2013, 52, 8-20. [CrossRef]

13. Evans, C.L.; Wightman, E.M.; Manlapig, E.V.; Coulter, B.L. Application of process mineralogy as a tool in sustainable processing. Miner. Eng. 2011, 24, 1242-1248. [CrossRef]

14. Ribeta, I.; Ptacek, C.J.; Blowes, D.W.; Jambor, J.L. The potential for metal release by reductive dissolution of weathered mine tailings. J. Contam. Hydrol. 1995, 17, 239-273. [CrossRef]

15. Gunsinger, M.R.; Ptacek, C.J.; Blowes, D.W.; Jambor, J.L. Evaluation of long-term sulfide oxidation processes within pyrrhotite-rich tailings, Lynn Lake, Manitoba. J. Contam. Hydrol. 2006, 83, 149-170. [CrossRef] [PubMed]

16. Cui, M.; Johannesson, K.H. Comparison of tungstate and tetrathiotungstate adsorption onto pyrite. Chem. Geol. 2017, 464, 57-68. [CrossRef] 
17. Hällström, L.P.B. Geochemical Characterization of Historical W, Cu and F Skarn Tailings at Yxsjöberg, Sweden. J. Geochem. Explor. 2018, 25, 33, 66-67.

18. Yang, J.; Niemistö, M. Tungsten deposits, mining and beneficiation techniques. In Proceedings of the Conference in Minerals Engineering 2017, Luleå, Sweden, 7-8 February 2017; Luleå University of Technology: Luleå, Sweden, 2017; pp. 161-174.

19. Das, A.; Sarkar, B. Advanced Gravity Concentration of Fine Particles: A Review. Miner. Process. Extr. Metall. Rev. 2018, 39, 359-394. [CrossRef]

20. Hällström, L.P.B.; Alakangas, L.; Martinsson, O. Geochemical characterization of W, Cu and F skarn tailings at Yxsjöberg, Sweden. J. Geochem. Explor. 2018, 194, 266-279. [CrossRef]

21. Geise, G.; LeGalley, E.; Krekeler, M.P.S. Mineralogical and geochemical investigations of silicate-rich mine waste from a kyanite mine in central Virginia: Implications for mine waste recycling. Environ. Earth Sci. 2011, 62, 185-196. [CrossRef]

22. Hübner, H. Molybdenum and tungsten occurrences in Sweden. Sver. Geol. Undersökning 1971, 46, 1-28.

23. Rothelius, E. The Ore Dressing Mill at the Yxsjöberg Mine. In Proceedings of the International Mineral Dressing Congress, Stockholm, Sweden, 1957. Yxsjöberg 1-15.

24. Khavari, P. Characterization of Historical Tungsten Ore Tailings for Pre-selection of Feasible Reprocessing Methods, Yxsjöberg, Sweden. Master's Thesis, Luleå University of Technology, Luleå, Sweden, September 2018; pp. 4-80.

25. Barthelmy, D. Mineralogy Database. Available online: http://www.webmineral.com/ (accessed on 21 January 2019).

26. Kupka, N.; Rudolph, M. Froth flotation of scheelite-A review. Int. J. Min. Sci. Technol. 2018, 28, 373-384. [CrossRef]

(C) 2019 by the authors. Licensee MDPI, Basel, Switzerland. This article is an open access article distributed under the terms and conditions of the Creative Commons Attribution (CC BY) license (http://creativecommons.org/licenses/by/4.0/). 